\title{
The Tax Elasticity of Capital Gains and Revenue-Maximizing Rates*
}

\author{
Ole Agersnap \\ Princeton University
}

\author{
Owen Zidar \\ Princeton University, NBER
}

December 23, 2020

\begin{abstract}
This paper uses a direct-projections approach to estimate the effect of capital gains taxation on realizations at the state level, and then develops a framework for determining revenue-maximizing rates at the federal level. We find that the elasticity of revenues with respect to the tax rate over a ten-year period is -0.5 to -0.3 , indicating that capital gains tax cuts do not pay for themselves, and that a 5 percentage point rate increase would yield $\$ 18$ to $\$ 30$ billion in annual federal tax revenue. Our long-run estimates yield revenue-maximizing capital gains tax rates of 38 to 47 percent.
\end{abstract}

\footnotetext{
*Agersnap: Princeton University (email: agersnap@princeton.edu); Zidar: Princeton University and NBER (email: ozidar@princeton.edu). We thank Coly Elhai and Stephanie Kestelman for providing excellent research assistance on this project. We also thank Alan Auerbach, Jerry Auten, Lily Batchelder, Tim Dowd, Patrick Driessen, Jane Gravelle, David Kamin, Paul Kindsgrab, Henrik Kleven, Ilyana Kuziemko, Robert McClelland, Jim Poterba, Natasha Sarin, Daniel Shaviro, Juan Carlos Suárez Serrato, Larry Summers, Danny Yagan, Eric Zwick, and anonymous referees as well as seminar and conference participants for helpful conversations and suggestions. This work is supported by National Science Foundation under Grant Number 1752431. We declare that we have no relevant or material financial interests that relate to the research described in this paper.
} 
The tax elasticity of capital gains realizations features centrally in U.S. fiscal policy debates. In the 1990s "capital gains tax wars," U.S. Treasury and economic officials argued that the responsiveness of realizations to capital gains tax rates was large enough that capital gains tax cuts would pay for themselves (Auten and Cordes, 1991). Others (e.g., Gravelle, 1991) asserted that the true responsiveness was much lower, so capital tax cuts would generate substantial fiscal cost. This issue has re-emerged in every presidential administration since 1990 and plays a key role in ongoing tax reform plans. For instance, this elasticity is the central parameter governing the revenue scores of Vice President Biden's plan to increase capital gains rates as well as President Trump's proposal reducing capital gains taxes.

Informing these policy debates is difficult because a wide range of estimates exist. Feldstein, Slemrod and Yitzhaki (1980), for example, estimate an elasticity with respect to the capital gains tax rate of -3.8, whereas the estimate of Burman and Randolph (1994) is -0.22 . Moreover, there is limited empirical evidence in recent decades when there has been lower inflation, more widespread use of diversified investment vehicles, and a bigger role of pass-through firms, which have accounted for nearly half of capital gains realizations in recent years (Smith, Yagan, Zidar and Zwick, 2019).

This paper estimates the effect of capital gains taxes on tax revenues and quantifies the implications for revenue-maximizing tax rates in the United States. We use a direct-projections approach and new state-level panel data on capital gains realizations and the migration of the wealthy to estimate the effects of state capital gains tax changes on realizations and location decisions. Our data, which range from 1980 to 2016, allow us to characterize responsiveness in a more recent period than most of the literature, and our direct-projections approach enables us to estimate effects over different time horizons and test for dynamic effects. We then build a simple framework to relate these state-level effects to a policy-relevant elasticity at the national level, which is the state-level realization response after removing migration effects and accounting for average state taxes and a minor aggregation adjustment term. We find that this policy-relevant elasticity of realizations with respect to capital gains tax rates over a ten year period is approximately -0.3 to -0.5 depending on the specification, and that the estimates are larger in absolute value in the short and medium run than in the long run.

We highlight three implications of these elasticity estimates. First, these estimates are well below an elasticity of one in absolute value, which indicates that capital gains tax cuts do not pay for themselves. We formally test and reject the null of an elasticity of -1.0. Second, these estimates suggest that raising capital gains tax rates by 5 percentage points (in the current regime with unlimited deferral and step-up-basis at death) would yield 18 to 30 billion in annual tax revenue, which is roughly twice the amount implied by the current approach of the Joint Committee on Taxation (JCT), which according to Gravelle (2020) currently uses an elasticity of -0.7 to score proposals. ${ }^{1}$ Third, our long-run elasticity estimates correspond to point estimates for the revenue-maximizing capital gains tax rates of 38 to 47 percent.

Using state-level panel data provides more reforms and closer comparison groups than time-series analysis at the federal level. At the federal level, there are not only fewer reforms but also many confounding factors.

\footnotetext{
${ }^{1}$ Gravelle (2020) also notes that Treasury had used an estimate of -1.0 previously, but has since moved closer to the JCT's estimate. In addition, Dowd, McClelland and Muthitacharoen (2015), whose paper first appeared as a technical working paper (JCX-56-12) of joint work of the staff of the JCT and CBO, estimate an elasticity of -0.72 .
} 
Figure 1 plots realizations and the maximum long-run capital gains tax rate since 1980. It shows that some capital gains tax changes are associated with sizable movements in realizations, but the responses are quite unequal across reforms. It is also quite difficult to separate these movements from unrelated macroeconomic trends and asset price fluctuations. One approach is to difference out macroeconomic trends by comparing the realization series in one county with that of a similar country. In panels (b) and (c) of Figure 1, we implement this approach using the realization series of the U.K. around cuts to the U.S. capital gains tax rate in 1997 and 2003. These panels, however, show how precarious this approach is - it yields unstable elasticity estimates that exhibit large variance in non-tax-related country-year shocks and inherits the limitations of cross-country regressions.

Our state-level approach complements prior work by Bogart and Gentry (1995), who use state panel data from 1979 to 1990 to estimate the effect of capital gains tax rates on on state-level realizations per tax return, and ongoing work by Bakija and Gentry (2014), who use a similar approach for a longer panel from 1950-2007. Relative to this valuable work, our paper uses a different empirical approach and new data to provide new policy-relevant elasticity estimates based on a more recent sample that is closer to current conditions in terms of inflation, pass-through prevalence, and tax code. By having a better measure of location decisions of the wealthy, our approach also provides a more accurate accounting for migration effects, and thus policy-relevant realization effects, which difference out migration responses. Moreover, we use a direct-projections approach that contributes new graphical evidence on the dynamics of realizations around tax changes. Scoring capital gains tax changes requires estimating how realizations evolve over a ten-year period around the tax change, which, to the best of our knowledge, has not been done in prior work.

Much of the literature on capital gains in the 1990s and 2000s (e.g., Burman and Randolph, 1994; Auerbach and Siegel, 2000; Poterba, 2002; Auten and Joulfaian, 2004) has focused on the distinction between temporary and permanent effects, and used individual-level data to estimate these effects. The interpretation of these individual-level results, however, is complicated by factors such as strategic loss-harvesting, observations with zero realizations, and movement in and out of top income brackets depending on the timing of big realizations. While standard approaches for addressing these concerns exist (e.g., selection corrections (Heckman, 1979) to account for realization decisions and instruments for tax rates), aggregating within a state-year cell avoids these complexities and also provides a longer panel than many existing individual-level studies. In addition, mapping estimates of micro-level responses, which are often person-weighted rather than dollar-weighted, into policy-relevant macro effects on tax revenues can be difficult. ${ }^{2}$ Indeed, Joint Committee on Taxation (1990) highlighted similar concerns when evaluating the available literature to score reforms during the capital tax wars. Some recent promising work using bunching approaches (e.g., Dowd and McClelland, 2019; Buhlmann, Doerrenberg, Loos and Voget, 2020) also faces the challenge of mapping bunching responses into policy-relevant elasticities. Our state-level approach has the benefit of estimating aggregate responses, while also providing considerable variation over a long panel.

\footnotetext{
${ }^{2}$ For example, choosing the weights (especially for those with losses) and accounting for heterogeneous responses introduces difficulties when aggregating from micro to macro.
} 


\section{Data on Capital Gains Taxation and Realizations}

Our primary outcome variable is realized capital gains by state and year from Smith, Zidar and Zwick (2020), which is the sum of short-term and long-term net realizations and is available from 1980 to 2016 . $^{3}$ We inflate nominal data using CPI-U from the Bureau of Labor Statistics to measure realizations in 2018 USD. We also use data from 1980 to 2016 on the number of wealthy individuals by state and year from Smith, Zidar and Zwick (2020). Specifically, we focus on the number of individuals in the top $10 \%$ and top $1 \%$ of the national wealth distribution. Finally, some specifications use population and output data from the US Census Bureau and the Bureau of Economic Analysis.

We relate these state-level outcomes to the net-of-capital-gains-tax rate in state $s$ in year $t$, which is $\left(1-\tau_{s, t}\right)$, where $\tau_{s, t}$ is the maximum marginal federal and state tax rate. This variable comes from NBER TAXSIM and measures the combined effect of federal and state taxes, incorporating the deductibility of state and local taxes, the phase-out of deductions, and other state-year-specific features of the tax code. For instance, in terms of deductibility, $1-\tau_{s t} \equiv 1-\tau_{t}^{\text {fed }}-\left(1-\tau_{t}^{\text {fed }}\right) * \tau_{\text {st }}^{\text {state }}$.

The tax rate data are available from 1977 to 2017, which is a slightly longer range of years than the realizations and count data. We use these extra years when estimating longer-term effects. For example, although we cannot use a state tax reform in 1978 to identify the short-term impact on realizations, it can still contribute to the identification of longer-term effects. ${ }^{4}$

Table 1 provides summary statistics. On average, state capital gains tax rates are 4 percent, but they range from 0 to 15 percent in our sample. Figure 1 plots the maximum federal tax rate over time. The current maximum capital gains tax rate is 23.8 percent. Combining both tax rates and accounting for interactions and phase-outs results in an effective keep rate of 75 percent on average, indicating that a dollar of realized capital gains amounts to 75 cents after taxes.

We find a total of 584 changes in state capital gains tax rates throughout our panel. Most of these changes are fairly small, which reflects the fact that our tax rate measure includes the effect of deductions and other minor provisions of state tax codes, so any changes to these provisions can cause the capital gains tax rate to change. The largest changes, however, are in excess of 4 percentage points (Table A.1). In total, we have 128 state tax changes that exceed 1 percentage point in absolute value. In Appendix Figure A.2, we provide a histogram of all changes. As we show below, our results are robust to using variation only from these larger tax changes.

We examine the relationship between changes in state capital gains tax rates and economic and policy conditions in Appendix Table A.2. Specifically, we regress indicators for capital gains tax increases and decreases on lags of state unemployment rates, GDP per capita, and state tax rates on personal and corporate income. ${ }^{5}$ Most coefficients are insignificant and small, though notably, higher unemployment in the previous year is associated with a higher probability of increasing the capital gains tax rate. In our main analysis, we

\footnotetext{
${ }^{3}$ The vast majority of realizations are long-term realizations (Appendix Figure A.3).

${ }^{4}$ We generally use the terms "reform" and "tax change" interchangeably to indicate any non-zero value of $\Delta \log \left(1-\tau_{s, t}\right)$.

${ }^{5}$ Appendix Table A.3 also shows that changes in state capital gains tax rates are often accompanied by changes in state personal income tax rates. We include specifications that do (as well as those that do not) control for leads and lags of changes in state tax rates on personal and corporate income.
} 
include specifications that condition on unemployment prior to tax reforms and do not find evidence that this relationship affects our estimates.

\section{Methods}

\subsection{Estimating the Annual Effects of Capital Gains Tax Changes}

We investigate the effects of log net-of-tax rates on log realized capital gains and on log counts of wealthy residents. We run direct projections regressions for different time horizons $h \in\{-10,-9, \ldots, 9,10\}$ :

$$
y_{s, t+h}=\beta_{h} \Delta \log \left(1-\tau_{s, t}\right)+\mathbf{X}_{s, t}^{\prime} \boldsymbol{\Lambda}_{h}+\gamma_{s, h}+\phi_{t, h}+\varepsilon_{s, t, h}
$$

where $s$ and $t$ index state and calendar year, $y_{s, t+h}$ is the outcome variable in year $t+h$ (log realized capital gains in our main specification), $\gamma_{s, h}$ and $\phi_{t, h}$ are horizon-specific state and year fixed effects, and $\mathbf{X}_{s, t}$ is a vector of controls. The main parameters of interest are the sequence of $\left\{\beta_{h}\right\}_{h=-10}^{10}$, which describe the path of realized capital gains around the tax change. The variable $\Delta \log \left(1-\tau_{s, t}\right)$ is the one-year change in the log net-of-tax rate. Using first differences helps deal with serial correlation concerns and facilitates estimating an impulse response function. To express the results as elasticities at different horizons, we normalize the coefficients to be relative to the coefficient in the year before the tax change, i.e., we define elasticities $\delta_{h} \equiv \beta_{h}-\beta_{-1}$. For example, $\delta_{5}=\beta_{5}-\beta_{-1}$ measures the elasticity of realized capital gains 5 years after the reform with respect to the capital gains net-of-tax rate, where the change in realizations is relative to the year before the tax event. We plot the $\delta_{h}$ estimates in our main figures.

In our baseline specification, we control for the vector $\mathbf{X}_{s, t}$ of leads and lags of changes in the log net-of-tax

rate, i.e., $\mathbf{X}_{s, t}^{\prime} \boldsymbol{\Lambda}_{\mathbf{h}}=\sum_{r=-10, r \neq 0}^{10} \lambda_{r}^{h} \Delta \log \left(1-\tau_{s, t+r}\right)$. Controlling for these other leads and lags of capital gains tax changes isolates the effect of a given tax reform. Without these controls, estimates would reflect the effect of not just the tax reform of interest, but also any other reforms occurring within the event window. ${ }^{6}$ To check robustness, we also run specifications featuring additional controls in $\mathbf{X}_{s, t}$, including GDP in pre-reform year $t-1$, GDP-growth-bin-by-year dummies, state unemployment in pre-reform year $t-1$, and changes in state corporate and personal income taxes. Finally, we include a specification that interacts the tax change with indicators based on the size of the tax change, and report estimates for $\beta_{h}$ coming only from larger tax reforms that exceed 1 percentage point in absolute value.

Discussion of Alternative Specifications and Semi-Elasticities. To facilitate comparisons to prior estimates, we discuss the theoretical and empirical implications of using logs and semi-logs in Appendix C. We also provide estimates using a semi-log specification, which delivers similar results. We prefer our net-of-tax

\footnotetext{
${ }^{6}$ In Appendix Figure A.9, we run a specification that excludes the vector of controls for other reforms and find similar results.
} 
formulation because it measures the relevant price governing behavior and is standard in the broader literature (Saez, Slemrod and Giertz, 2012).

Compared with an event-study specification, which centers around the outcome year rather than the policy reform year, the direct projections approach accurately recovers elasticities in simulations (see Appendix D for details). ${ }^{7}$ In the appendix we also provide results using event-study specifications (Appendix Figure A.8, Figure A.13 and Table A.5). Results are similar.

\subsection{Estimating effects over multiple years}

We extend the method in equation (1) to estimate the elasticity of capital gains realizations over longer time horizons. First, we consider a direct projections specification that estimates the effect of tax reforms on realizations in three-year bins, yielding estimates of the elasticity in the short (0-2 years), medium (3-5 years) and longer run (6-8 years):

$$
y_{s, t+h}=\tilde{\beta}_{h} \Delta_{3} \log \left(1-\tau_{s, t}\right)+\mathbf{X}_{s, t}^{\prime} \tilde{\Lambda}_{h}+\tilde{\gamma}_{s, h}+\tilde{\phi}_{t, h}+\tilde{\varepsilon}_{s, t, h},
$$

where $\Delta_{3} \log \left(1-\tau_{s, t}\right)$ represents the three-year change in the $\log$ net-of-tax rate (i.e., $\Delta_{3} \log \left(1-\tau_{s, t}\right)=$ $\left.\log \left(1-\tau_{s, t}\right)-\log \left(1-\tau_{s, t-3}\right)\right)$. For each value of $h \in-9,-6, \ldots, 6,9$, we estimate a separate instance of this regression. The controls for other reforms in this regression are also specified in 3-year bins: the vector of controls $\mathbf{X}_{s, t}$ now contains the variables $\Delta_{3} \log \left(1-\tau_{s, t+r}\right)$ for $r=-9,-6,-3,3,6,9$. We use the notation $\tilde{\beta}$, $\tilde{\Lambda}$, etc, to distinguish the parameters in equation (2) from their analogues in equation (1).

To understand why this specification correctly identifies the average elasticity over the specified three-year periods, consider a simple example. Suppose a state changes its capital gains tax rate exactly once in year 2000. Then $\Delta_{3} \log \left(1-\tau_{s, t}\right)$ takes a value of zero for this state in every year except three: $t=2000,2001,2002$. Now consider the regression above for $h=0$. The variable $\Delta_{3} \log \left(1-\tau_{s, t}\right)$ is non-zero whenever the left-hand side variable is $y_{s, 2000}, y_{s, 2001}$ or $y_{s, 2002}$. Therefore, the coefficient $\tilde{\beta}_{0}$ will capture the average effect of the tax reform on capital gains in these three years. Suppose instead $h=-3$. In this case, our left-hand side variable of $y_{s, t+h}$ becomes $y_{s, t-3}$. Since $\Delta_{3} \log \left(1-\tau_{s, t}\right)$ is still zero for all $t$ except 2000, 2001, and 2002, $\tilde{\beta}_{-3}$ captures the effect of the tax reform on $y_{s, 1997}, y_{s, 1998}$ and $y_{s, 1999}$ (the only $y_{s, t-3}$ such that $t \in 2000,2001,2002$ ). Now, define $\tilde{\delta}_{0} \equiv \tilde{\beta}_{0}-\tilde{\beta}_{-3}$. The parameter $\tilde{\delta}_{0}$ measures the difference in realizations in the periods immediately after and before the reform. In our example, $\tilde{\delta}_{0}$ represents the difference between average realizations in post-reform years 2000-2002 and average realizations in pre-reform years 1997-1999. In other words, $\tilde{\delta}_{0}$ identifies the average elasticity over a $0-2$ year horizon relative to the reform year. Similarly, $\tilde{\delta}_{3} \equiv \tilde{\beta}_{3}-\tilde{\beta}_{-3}$ would identify the impact of the reform on the difference between average realizations in 2003-2005 and 1997-1999, thus giving us an average elasticity over a 3-5 year horizon, and so on.

We use a similar approach to estimate effects in the post period (i.e., in years 0-10) and in the long-run

\footnotetext{
${ }^{7}$ Since the direct-projections approach centers leads and lags on the policy reform year, it includes fewer pre-observation controls when estimating the effect of post-observation reforms or vice versa. However, it also facilitates controlling for pretreatment conditions and handling locations with multiple events (and associated issues with adjusting standard errors).
} 
(i.e., years 6-10). To get a single estimate of the effect of capital gains tax reforms on realizations in the decade following the reform, we use the following specification:

$$
y_{s, t}=\beta_{\ell} \Delta_{11} \log \left(1-\tau_{s, t}\right)+\mathbf{X}_{s, t}^{\prime} \dot{\boldsymbol{\Lambda}}_{h}+\dot{\gamma}_{s, h}+\dot{\phi}_{t, h}+\dot{\varepsilon}_{s, t, h},
$$

where $\Delta_{11} \log \left(1-\tau_{s, t}\right)=\log \left(1-\tau_{s, t}\right)-\log \left(1-\tau_{s, t-11}\right) .{ }^{8}$ To estimate the elasticity for the 0-10-year estimate, we take the point estimate $\beta_{\ell}$ from this regression and subtract off the point estimate $\tilde{\beta}_{-3}$ from (2). Finally, the long-run estimate for years 6-10 is implemented similarly to equation (3), but using a 5-year rather than 11-year difference for the right-hand side tax change variable (i.e., replacing $\Delta_{11}$ with $\Delta_{5}$ ), and using $y_{s, t+6}$ as the outcome variable.

\section{Capital Gains Tax Changes and Realizations at the State-Level}

Figure 2 shows the results of our baseline specification from equation (1). The figure illustrates how capital gains realizations evolve before and after a change in the capital gains net-of-tax rate, controlling for other state capital tax reforms. We see no clear pre-trend: in each of the ten pre-reform years, capital gains realizations tend to be stable. We then see a jump soon after the reform, after which the point estimates decline modestly throughout the post-period. Unlike the 1986 and 2012 national reforms shown in Figure 1, we do not see evidence of anticipation effects preceding state capital gains tax reforms, which would have manifested as a downward spike at year -1 .

On average across post-reform years 0 through 10, the point estimates directly provide an elasticity estimate of capital gains realizations with respect to the net-of-tax rate of around 3.18. The dynamics of this response are also of interest. In Figure 2, there is a modest downward trend over the post-period. Combining some of our individual year point estimates, the estimated short-run elasticity $\frac{1}{3} \sum_{h=1}^{3} \hat{\delta}_{h}$ is 3.61 (s.e. 1.22), whereas

the longer run estimate $\frac{1}{3} \sum_{h=8}^{10} \hat{\delta}_{h}$ is somewhat lower at 2.59 (s.e. 1.42). However, we cannot reject the null that these effects are the same.

In Panel (b) of Figure 2, we present five robustness tests of these results: (1) controlling for pre-event state GDP, (2) controlling for pre-event state GDP growth, (3) controlling for pre-event state unemployment rates, (4) only using large reforms that change the capital gains tax rate by at least 1 percentage point, and (5) controlling for changes in state income and corporate tax rates. The results are remarkably similar. We also provide a range of other robustness checks in the Appendix Figures A.7-A.12, including an event study version of the analysis, a specification without controls for other capital gains tax changes in the pre- and post-reform periods, and separate analyses for small and large states

State capital gains tax rates often move in the same direction as state income tax rates (Appendix Table A.3). Many states treat capital gains as regular income for tax purposes, in which case the capital gains tax rate will be identical to the income tax rate. We account for these possibilities using a specification that controls for

\footnotetext{
${ }^{8}$ In this specification, the vector of controls $\mathbf{X}_{s, t}$ contains variables that are still 3-year binned versions before and after the long bin: $\Delta_{3} \log \left(1-\tau_{s, t+r}\right)$ for $r=-17,-14,-11,3,6,9$.
} 
changes in personal income and corporate taxes. Panel (b) of Figure 2 illustrates that the elasticity estimates from this specification are very similar to the baseline.

\section{Federal Revenue-Maximizing Rates}

In this section, we present a framework that shows how to use the state-level estimates from above to infer the policy-relevant elasticity at the national level. We then derive an estimate for the revenue-maximizing tax rate and calculate revenue effects of a hypothetical five percentage point tax rate increase.

\subsection{A Simple Model of State-Level Capital Gains Realizations}

Consider a country with states $s \in S$. Residents of state $s$ retain a share $\left(1-\tau_{F}-\tau_{s}\right)$ of their realized capital gains after paying federal $\left(\tau_{F}\right)$ and state capital gains taxes $\left(\tau_{s}\right) .^{9}$

We can decompose total realized capital gains in state $s$ into two terms:

$$
C G_{s}=N_{s}\left(1-\tau_{F}-\tau_{s}, \tau_{-s}\right) R_{s}\left(1-\tau_{F}-\tau_{s}\right)
$$

where $N_{s}\left(1-\tau_{F}-\tau_{s}, \tau_{-s}\right)$ represents the number of residents in state $s$, and $R_{s}\left(1-\tau_{F}-\tau_{s}\right)$ represents realized capital gains per resident conditional on residing in state $s$.

Using equation (4), we can decompose the empirical elasticity of capital gains with respect to the net-of-tax rate:

$$
\varepsilon^{C G}=\frac{\partial \log C G_{s}}{\partial \log \left(1-\tau_{F}-\tau_{s}\right)}=\frac{\partial \log N_{s}}{\partial \log \left(1-\tau_{F}-\tau_{s}\right)}+\frac{d \log R_{s}}{d \log \left(1-\tau_{F}-\tau_{s}\right)}=\varepsilon^{N}+\varepsilon^{R} .
$$

Thus, $\varepsilon_{s}^{C G}$ is the sum of two elasticities: a migration elasticity $\varepsilon^{N}$ and a realization elasticity $\varepsilon^{R}$, which is the main object of interest and represents the "pure" per capita response of capital gains realizations to the net-of-tax rate.

\subsection{From State-Level Realizations to the Federal Revenue-Maximizing Tax Rate}

We show in Appendix Section E shows that the federal capital gains tax rate that maximizes federal tax revenue from capital gains is:

$$
\tau_{F}^{*}=\frac{1-\bar{\tau}_{S}}{1+\varepsilon^{R}} .
$$

This formula resembles familiar optimal tax models (Saez, 2001; Diamond and Saez, 2011), but has an additional aggregation adjustment term $\bar{\tau}_{S}$ that denotes the average population-weighted state tax rate. The policyrelevant elasticity at the federal level is our estimate of the elasticity of capital gains realizations at the state level less the migration elasticity, i.e., $\varepsilon^{R}=\varepsilon^{C G}-\varepsilon^{N}$.

\footnotetext{
${ }^{9}$ When measuring keep rates net of federal and state taxes, we account for deductibility as described in section 1.
} 


\subsection{Estimating the Federal Revenue-Maximizing Tax Rate}

We estimate $\varepsilon^{N}$ based on the responses of those at the top of the national wealth distribution because the top groups account for essentially all capital gains (Smith, Zidar and Zwick, 2020). To do so, we fit equation (1) when the outcome is the share of the state population that belongs to either the top $10 \%$ or the top $1 \%$ of the national wealth distribution. Panels (a) and (b) of Figure 3 show the outcome of this specification for the top $10 \%$ and top $1 \%$ groups, respectively. We see fairly stable pre-trends, though somewhat noisy in the earliest pre-periods for the top $1 \%$ group. Following an increase in the net-of-tax rate, the share of residents in each of the top groups grows, and the magnitude of the response is larger for the top $1 \%$ group.

Connecting these migration responses to the theory requires weighing the following tradeoff. Focusing on the top $10 \%$ delivers a more precise estimate, but risks putting too little weight on the responsiveness of those at the top who have substantial capital gains realizations in dollar terms. Our preferred measure of migration is a combination of the two groups. Specifically, we define the outcome variable as: $\theta_{s} \ln N_{s, t}^{P 99-P 100}+(1-$ $\left.\theta_{s}\right) \ln N_{s, t}^{P 90-P 100}$, which is a dollar-weighted convex combination of the two groups, where $\theta_{s}$ is the state's wealth share of the top $1 \%$ relative to the top $10 \%{ }^{10}$

To estimate $\varepsilon^{R}$, we first estimate $\varepsilon^{C G}$ and $\varepsilon^{N}$ using our binned specifications described in section 2.2, with log capital gains and our migration measure from above as outcome variables. We perform this estimation at various time horizons: the main estimate covering years 0-10 after each reform, as well as three-year bins of 0-2 years, 3-5 years, 6-8 years, and 6-10 years. We then calculate $\hat{\varepsilon}_{h}^{R}=\hat{\varepsilon}_{h}^{C G}-\hat{\varepsilon}_{h}^{N}$ at each time horizon.

Panel (c) of Figure 3 shows the estimates from these binned regressions graphically. The grey series shows estimates of $\hat{\varepsilon}_{h}^{C G}$ at different horizons $h$, the dark blue series shows $\hat{\varepsilon}_{h}^{R}$, and the light blue shows the average policy-relevant elasticity over a decade following each reform, $\hat{\varepsilon}_{0-10}^{R}$.

Table 2 also provides estimates of our elasticities at various time horizons. We also translate our net-of-tax elasticity estimates into an elasticity with respect to the tax rate to facilitate comparisons to prior work. Table 2 includes estimates from two alternative specifications: one in which we identify all elasticities from state tax reforms of at least 1 percentage point, and a second in which we control for all reforms to state income tax and corporate tax rates in a 21-year window around the capital gains tax reform in question. ${ }^{11}$

Overall, our baseline estimate at a 0-10 year horizon gives an elasticity with respect to the net-of-taxrate of approximately 1.87 , which translates into an elasticity of -0.53 with respect to the tax rate. The specification using only large tax changes yields an elasticity with respect to the tax rate of -0.42 and the specification controlling for other state tax changes yields an elasticity with respect to the tax rate of -0.29. While these point estimates are somewhat noisy, the point estimates are notably smaller in absolute value than the conventional elasticities used by tax analysts. Moreover, we can definitively test and reject the null

\footnotetext{
${ }^{10} \theta_{s}$ is defined as

$$
\theta_{s}=\sum_{t} \frac{W_{s, t}^{P 99-P 100}}{W_{s, t}^{P 90-P 100}}
$$

that is, it represents the average wealth share in state $s$ of the top $1 \%$ within the top $10 \%$ across all years in our sample. Across all states in the sample, the mean of $\theta_{s}$ is 0.39 . The minimum value is 0.28 (Iowa), while the maximum is 0.56 (District of Columbia), with Wyoming, Nevada and New York also having values above 0.5.

${ }^{11}$ Appendix Tables A.6 and A.7 provide additional specifications that control for pre-reform unemployment and unemployment growth. These are very similar to the results in Table 2.
} 
hypothesis that this elasticity with respect to the tax rate equals 1 in absolute value. The p-values for the baseline, big-change-only, and other-tax-control specifications are 0.066, 0.021, and 0.31, respectively. This finding provides important evidence suggesting that capital gains tax cuts do not pay for themselves, which has been a prominent proposition in this literature (Joint Committee on Taxation, 1990; Auten and Cordes, 1991; Gravelle, 1991; Burman, 2010; Gravelle, 2020).

As in Figure 2, the results in Table 2 across all specifications show an elasticity which is somewhat bigger in absolute value in the short to medium run, and then declines in the longer run. This pattern could potentially reflect some transitory effects that are present in the short run but disappear over time. For instance, a tax cut may in the shorter run spur some individuals to realize accumulated gains to take advantage of the lower tax rate, particularly if they expect a possible reversal of the tax cut in the future. However, once many of these accumulated gains have been realized, the potential for realization of further gains is limited, and the magnitude of the behavioral effect declines in the longer run. ${ }^{12}$ For this reason, we view our 6-10 year estimates as being the most likely to capture the long-run structural elasticity of capital gains to the net-of-tax rate, though some transitory effects might exist even beyond a 10-year horizon.

\subsection{Policy Implications}

These elasticity results have policy implications for revenue-maximizing tax rates and the revenue effects of capital gains tax reforms. Table 2 provides the corresponding estimates of the revenue-maximizing tax rate, $\hat{\tau}_{F}^{*}$. Our baseline elasticity estimate for the full 10-year period implies a revenue-maximizing rate around $33 \%$, and the analogous estimates for the big-changes-only and control-for-other-tax-changes specifications are $38 \%$ and $47 \%$, respectively. Thus, over a ten year budget window, these results suggest that a capital gains tax rate of around $40 \%$ would maximize federal capital gains tax revenues. For analysis over years 6-10, we find somewhat higher revenue maximizing rates, ranging from $38 \%$ to $47 \%$ across the three specifications.

We can use our elasticities from Table 2 to estimate how realizations and thus tax revenues change in response to a 5 percentage point tax increase. By the definition of these elasticities, we can estimate how realizations and thus tax revenues change for a given elasticity estimate and tax rate change. In 2017, the most recent year that our state and federal tax data covers, the average combined maximum state and federal tax rate was $27.82 \%{ }^{13}$ We use this rate as an approximation to the average marginal tax rate. An increase of 5 percentage points in the tax rate implies that the net-of-tax rate decreases by $\frac{0.05}{1-0.2782}=6.93 \%$. We relate this percentage change in taxes to a percentage change in realizations using our baseline 0-10 year policy-relevant elasticity of 1.87 from Table 2, and find that realizations would have been $6.93 \times 1.87=13$ percent lower, for a total of $\$ 754.3$ billion in realizations. To calculate counterfactual tax revenue given this realizations amount, we need to use the average tax rate, which differs from the marginal. In 2018, the most recent year for which

\footnotetext{
${ }^{12}$ This possibility seems consistent with the graphical evidence that we find when we examine the behavioral effects following tax increases and tax decreases separately, which are shown in Appendix Figure A.10. Following a tax cut, we see a striking and immediate upward jump in realizations, and the effect grows even larger over the following 3-4 years. However, after this initial jump, the trend reverses, and the behavioral effect 7-9 years after a tax cut is much more modest. In contrast, the effect on realizations following a tax increase is much smaller and more stable over time.

${ }^{13}$ Appendix Figure A.6 shows how the following calculations would change if the elasticity were measured at a different initial tax rate.
} 
we have data on federal tax revenue, total capital gains realizations were $\$ 890.6$ billion (Piketty, Saez and Zucman, 2018), and federal capital gains tax revenue was $\$ 158.4$ billion, yielding an average federal tax rate

of $\frac{158.4}{890.6}=17.79 \%$. We assume that the 5 percentage points tax increase also applies to this number, for a counterfactual average tax rate of $17.79+5=22.79 \%$. Applying this average tax rate to the counterfactual realizations amount yields tax revenue of $0.2279 \times 754.3=\$ 176.6$ billion, an increase of $\$ 18.2$ billion relative to the actual 2018 tax revenue. Repeating these steps, but using the net-of-tax elasticity estimate of 1.01 from our specification with controls for other taxes would result in an increase of $\$ 30.3$ billion in tax revenues. In sum, we estimate that a 5 percentage point tax increase would yield between $\$ 18$ billion and $\$ 30$ billion in additional revenues.

Absent any behavioral response, which corresponds to an elasticity of zero, tax revenues from this 5 percentage point tax increase would increase revenues by $\$ 44.5$ billion. Thus, depending on the specification, our estimates indicate that, at current tax rates, between a third and half of the mechanical revenue gains are lost due to behavioral effects.

Our central elasticity estimate is lower than those in most existing studies, and our estimated revenuemaximizing tax rate is correspondingly higher. In particular, it is interesting to compare our estimated elasticity to that used by the JCT to evaluate the budgetary impacts of tax reforms. They currently assume an elasticity with respect to the tax rate of 0.68 (Gravelle, 2020), substantially higher than our estimate. This elasticity would imply a revenue gain from a 5 percentage point tax increase of only $\$ 10.6$ billion, or that about threequarters of mechanical revenue gains are lost due to behavioral effects. Appendix Figure A.1 compares our elasticity estimate, implied revenue-maximizing tax rate, and revenue impact with estimates implied by previous studies. Note that all of these estimates apply to the current capital taxation regime with unlimited deferral and step-up-basis at death.

\section{Conclusion}

This paper estimates the effect of state capital gains tax changes on realizations at the state-level. These estimates reflect the responsiveness of both capital gains realizations as well as the migration of the wealthy. These overall effects at the state-level are of interest in their own right as many states consider revenue-raising options to address budgetary pressures. We hope that estimates of how state-level realizations evolve around state capital gains tax changes may serve as useful inputs into this process, as well as to the literature on state taxes, capital gains behavior, and migration.

We also provide policy-relevant elasticities at the federal level, which use a new framework to account for migration responses on the wealthy and other aggregation adjustments. Our main estimate is an elasticity of realizations with respect to the tax rate of -0.5 to -0.3 depending on the specification.

These main elasticity estimates are notably smaller than estimates used by official analysts to score federal tax reforms (Gravelle, 2020). We hope that these elasticity estimates, as well as their implications for revenuemaximizing rates and tax revenue effects, will be considered when evaluating reforms to capital gains taxation, 
although we note that using these estimates to evaluate large tax rate changes may require extrapolation beyond the observed variation in our sample. In addition, revenue-maximizing rates may exceed welfare-maximizing rates to the extent that capital gains taxes reduce investment below optimal levels or create lock-in effects that misallocate capital. Overall, our bottom-line finding is that raising capital gains tax rates has sizable revenue-raising potential, and that cutting capital gains tax rates has substantial fiscal cost. 


\section{References}

Auerbach, Alan J, and Jonathan M Siegel. 2000. "Capital-gains realizations of the rich and sophisticated." American Economic Review, 90(2): 276-282.

Auten, Gerald, and David Joulfaian. 2004. "Taxes and Capital Gains Realizations: Evidence from a Long Panel." Vol. 5.

Auten, Gerald E, and Joseph J Cordes. 1991. "Policy watch: cutting capital gains taxes." Journal of Economic Perspectives, 5(1): 181-192.

Bakija, Jon M, and William M Gentry. 2014. "Capital gains taxes and realizations: Evidence from a long panel of state-level data." Unpublished Manuscript, Williams College.

Board of Governors of the Federal Reserve System. 1971-2019. "U.S. / U.K Foreign Exchange Rate[AEXUSUK]." https://fred.stlouisfed.org/series/AEXUSUK (accessed Dec. 9, 2020).

Bogart, William T, and William M Gentry. 1995. "Capital gains taxes and realizations: Evidence from interstate comparisons." The Review of Economics and Statistics, 267-282.

Buhlmann, Florian, Philipp Doerrenberg, Benjamin Loos, and Johannes Voget. 2020. "How do taxes affect the trading behavior of private investors? Evidence from individual portfolio data." Working Paper.

Bureau of Economic Analysis. 1963-2019. "Regional Economic Accounts: Download." https://apps . bea. gov/regional/downloadzip.cfm (accessed May 7, 2020).

Bureau of Labor Statistics. 1913-2020. "Consumer Price Index - All Urban Consumers." https://www. bls.gov/cpi/data.htm (accessed May 7, 2020).

Bureau of Labor Statistics. 1976-2019. "Local Area Unemployment Statistics." https://www.bls.gov/ lau/\#data (accessed June 19, 2019).

Burman, Leonard E. 2010. The labyrinth of capital gains tax policy: A guide for the perplexed. Brookings Institution Press.

Burman, Leonard E, and William C Randolph. 1994. "Measuring permanent responses to capital-gains tax changes in panel data." The American Economic Review, 794-809.

Diamond, Peter, and Emmanuel Saez. 2011. "The case for a progressive tax: from basic research to policy recommendations." Journal of Economic Perspectives, 25(4): 165-90.

Doerrenberg, Phillipp, Andreas Peichl, and Sebastian Siegloch. 2017. "The elasticity of taxable income in the presence of deduction possibilities." Journal of Public Economics, 151: 41-55.

Dowd, Tim, and Robert McClelland. 2019. "The bunching of capital gains realizations." National Tax Journal, 72(2): 323-358.

Dowd, Tim, Robert McClelland, and Athiphat Muthitacharoen. 2015. "New evidence on the tax elasticity of capital gains." National Tax Journal, 68(3): 511.

Feenberg, Daniel Richard, and Elizabeth Coutts. 1960-2018. "Marginal Tax Rates by Income Type." https://users.nber.org/ taxsim/marginal-tax-rates/ (accessed Feb. 22, 2019).

Feenberg, Daniel Richard, and Elizabeth Coutts. 1977-2017. "Maximum State Income Tax Rates." https://users.nber.org/ taxsim/state-rates/ (accessed Jan. 21, 2019).

Feldstein, Martin, Joel Slemrod, and Shlomo Yitzhaki. 1980. "The effects of taxation on the selling of corporate stock and the realization of capital gains." The Quarterly Journal of Economics, 94(4): 777-791.

Gravelle, Jane. 1991. "Limits to Capital Gains Feedback Effects." Congressional Research Service, Library of Congress. 
Gravelle, Jane G. 2020. "Capital Gains Tax Options: Behavioral Responses and Revenues." Vol. 41364.

Gruber, Jon, and Emmanuel Saez. 2002. "The elasticity of taxable income: evidence and implications." Journal of Public Economics, 84: 1-32.

Heckman, James J. 1979. "Sample selection bias as a specification error." Econometrica: Journal of the econometric society, 153-161.

HM Revenue and Customs. 1980-2017b. "National Statistics: Rates of Capital Gains Tax." https://www . gov.uk/government/statistics/rates-of-capital-gains-tax-statistics (accessed May 6, 2019).

HM Revenue and Customs. 1987-2017a. "National Statistics: Capital Gains Tax statistical tables." https: //www.gov.uk/government/statistics/capital-gains-tax-statistical-tables (accessed June 10, 2019).

Internal Revenue Service. 1985, 1997-1999, 2007-2012. "SOI Tax Stats - Sales of Capital Assets Reported on Individual Tax Returns." https://www.irs.gov/statistics/ soi-tax-stats-sales-of-capital-assets-reported-on-individual-tax-returns (accessed November 16, 2020).

Internal Revenue Service. 1997-2016. "SOI Tax Stats - Historic Table 2." https://www.irs.gov/ statistics/soi-tax-stats-historic-table-2 (accessed June 19, 2019).

Joint Committee on Taxation, Staff. 1990. "Explanation of Methodology Used to Estimate Proposals Affecting the Taxation of Income from Capital Gains." Vol. JCS-12-90.

Kleven, Henrik, and Esben Schultz. 2014. "Estimating Taxable Income Responses Using Danish Tax Reforms." American Economic Journal: Economic Policy, 6: 271-301.

Moffitt, Robert A., Brian J. Phelan, and Anne E. Winkler. 1960-1998. "Welfare Benefits Data Base." http://www.econ2.jhu.edu/people/moffitt/datasets.html (accessed June 19, 2019).

OECD.Stat. 1965-2018. "Details of Tax Revenue - United States." https://stats.oecd.org/Index.aspx? DataSetCode=REVUSA (accessed May 27, 2020).

Office for National Statistics. 1988-2020. "Consumer price inflation time series." https://stats.oecd. org/Index . aspx?DataSetCode=REVUSA (accessed May 6, 2020).

Piketty, Thomas, Emmanuel Saez, and Gabriel Zucman. 2018. "Distributional national accounts: methods and estimates for the United States." Quarterly Journal of Economics, 133(2): 553-609.

Poterba, James M. 2002. "Taxation, risk-taking, and household portfolio behavior." In Handbook of Public Economics. Vol. 3, 1109-1171. Elsevier.

Saez, Emmanuel. 2001. "Using elasticities to derive optimal income tax rates." The Review of Economic Studies, 68(1): 205-229.

Saez, Emmanuel, Joel Slemrod, and Seth H. Giertz. 2012. "The Elasticity of Taxable Income with Respect to Marginal Tax Rates: A Critical Review." Journal of Economic Literature, 50(1): 3-50.

Slattery, Cailin, and Owen Zidar. 2020. "Evaluating State and Local Business Incentives." Journal of Economic Perspectives, 34(2): 90-118.

Smith, Matthew, Danny Yagan, Owen Zidar, and Eric Zwick. 2019. "Capitalists in the Twenty-first Century." Quarterly Journal of Economics, 134(4): 1675-1745.

Smith, Matthew, Owen M Zidar, and Eric Zwick. 2020. "Top Wealth in America: New Estimates and Implications." Working Paper.

Tax Policy Center. 1913-2014. "Historical Highest Marginal Income Tax Rates." https://www. taxpolicycenter.org/statistics/historical-highest-marginal-income-tax-rates (accessed June $3,2020)$. 
US Census Bureau. 1951-2019b. "Annual Survey of State Government Tax Collections Datasets." https: //www.census.gov/programs-surveys/stc/data/datasets.html (accessed May 28, 2020).

U.S. Census Bureau. 1960-2019a. "Annual Estimates of the Population for the U.S. and States, and for Puerto Rico." https://fred.stlouisfed.org/release/tables?rid=118\&eid=259194 (accessed Jan. 13, 2020). 
Figure 1: Capital Gains Realizations and Tax Rates in the United States

(a) Time-Series Evidence

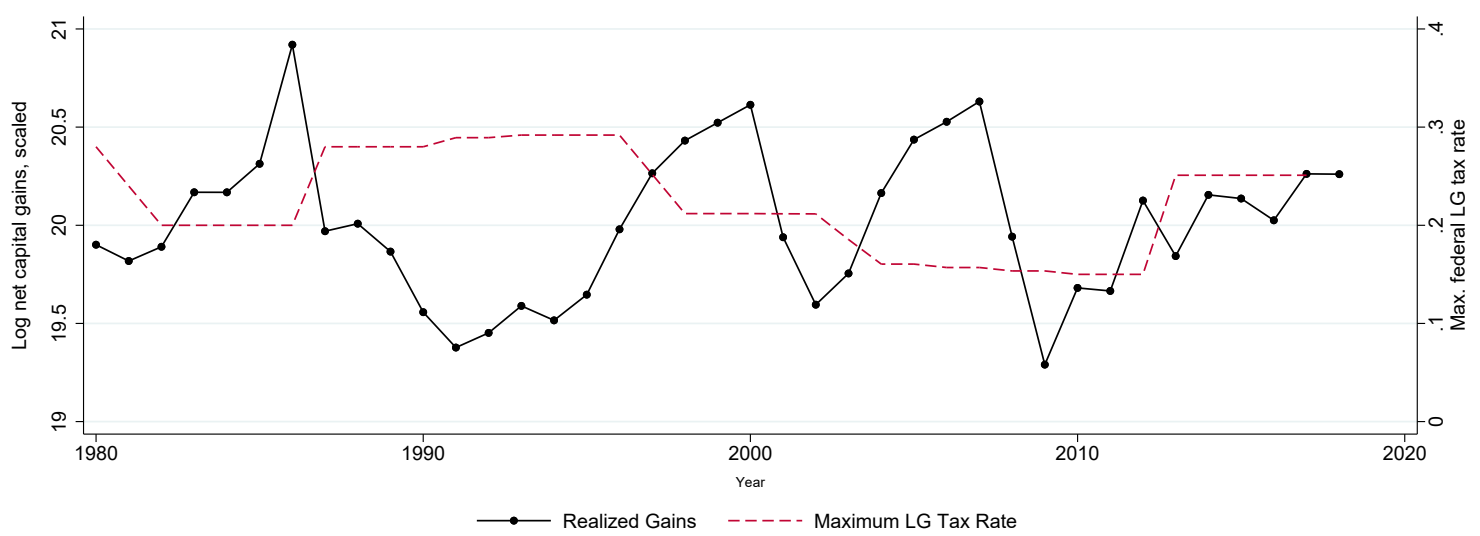

(b) US vs. UK: 1997 Reform

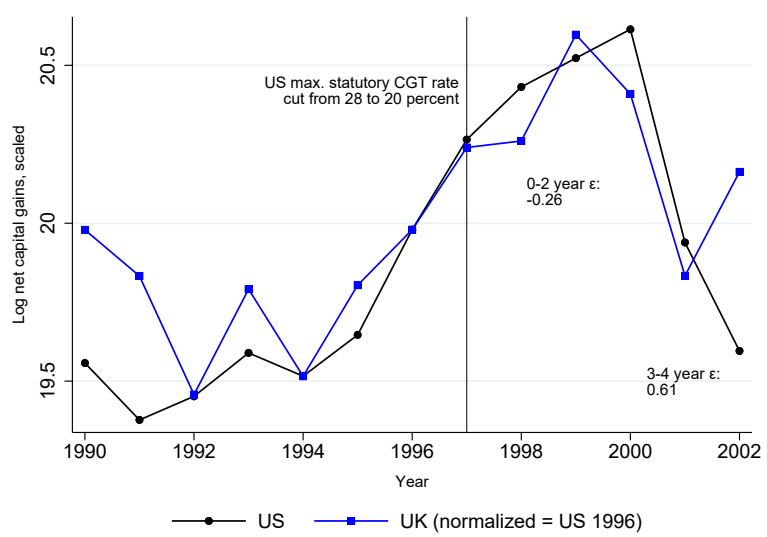

(c) US vs. UK: 2003 Reform

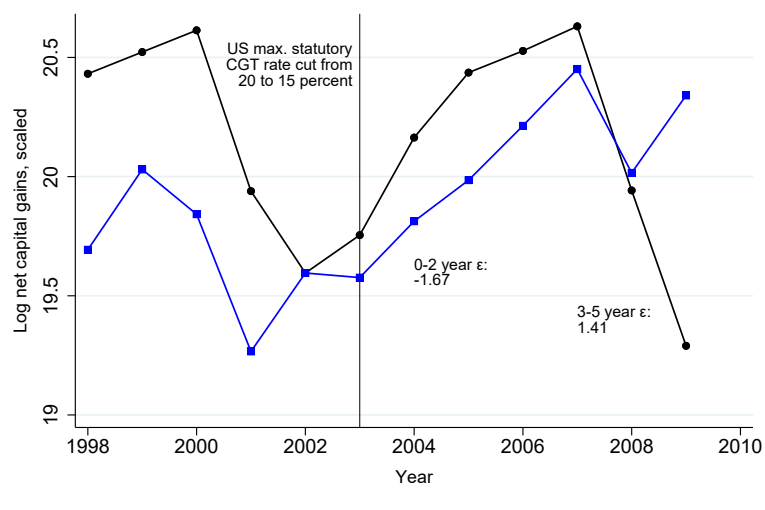

Notes: In all panels, net capital gains have been scaled by the ratio of a country's real GDP in 2000 to the country's real GDP in a given year (e.g. U.S. capital gains for 2005 were multiplied by the U.S. GDP in 2000 divided by the U.S. GDP in 2005). Panel (a) shows the evolution of realized capital gains and the maximum federal long-term capital gains tax rate in the US from 1980 to 2018. Panels (b) and (c) compare realized capital gains in the US to those in the UK around the time of US reforms. In all panels, net capital gains have been scaled by the ratio of a given country-year's GDP to the country's GDP in 2000. In both (b) and (c), the UK capital gains tax rate was constant throughout the period shown. The UK series has been normalized to equal the US series in the year prior to the reform. We calculate the short-term (0-2 years) and medium-term (3-4 or 3-5 years) tax elasticities provided in panels (b) and (c) by normalizing the UK series in the year before reform, calculating the average difference between the normalized UK series and the US series during the period, and dividing that difference by the difference in US log net-of-tax rates before and after the reform. This calculation gives us elasticities with respect to the net-oftax rate, which we then multiply by $\frac{-0.22}{1-0.22}$ to convert them into elasticities with respect to the tax rate, at a tax rate of $22 \%$. We use this tax rate to facilitate comparisons between these numbers and those given in Table 2, where we also use a rate of $22 \%$ to calculate tax elasticities given net-of-tax elasticities. If instead we had calculated the tax elasticities in panels (b) and (c) using the prevailing US federal tax rates prior to each reform, we would have obtained tax elasticities in panel (b) of - 0.48 in the short run and 0.85 in the medium run, and in panel (c) of -1.64 in the short run and 1.28 in the medium run. We do not include the fifth year post-reform in the medium-term analysis of panel (b) because this fifth year coincides with the 2003 tax reform shown in panel (c). 
Figure 2: The Effect of Net-of-Tax Rate Changes on Capital Gains Realizations

(a) Baseline

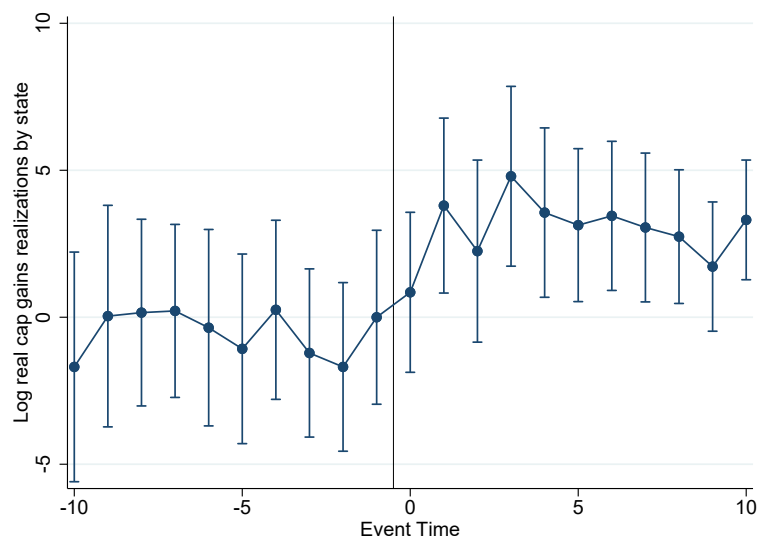

(b) Alternate specifications

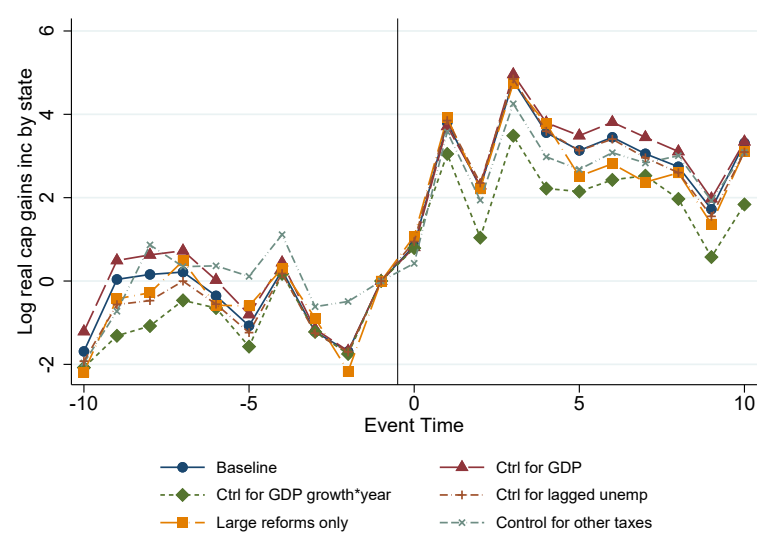

Notes: This figure presents our main results of the impact of state capital tax rate changes on capital gains realizations. The points plotted are the estimated coefficients from equation (1) for the impact of a change in the total (federal and state) log net-of-tax capital gains tax rate on log capital gains realizations. The alternate specifications include the following: (1) controlling linearly for GDP in the year before the reform; (2) controlling for a set of dummies interacting prior GDP growth tertiles and years, where the prior GDP growth tertile is determined using GDP growth over the most recent three years; (3) controlling for prior unemployment rates; (4) interacting the tax change variable with indicators for reforms greater or smaller than 1 percentage point, and reporting the coefficients corresponding to large changes, and (5) controlling for other state personal and corporate income tax changes. Specifically, for (4) we modify the baseline specification by estimating separate coefficients for large and small tax changes, i.e., we fit $y_{s, t+h}=\beta_{h}^{\text {big }} \times \mathbf{1}\left(\left|\Delta\left(1-\tau_{s, t}^{\text {state }}\right)\right| \geq 0.01\right) \times \Delta \log \left(1-\tau_{s, t}\right)+\beta_{h}^{\text {small }} \times$ $\mathbf{1}\left(\left|\Delta\left(1-\tau_{s, t}^{\text {state }}\right)\right|<0.01\right) \times \Delta \log \left(1-\tau_{s, t}\right)+\mathbf{X}_{s, t}^{\prime} \boldsymbol{\Lambda}_{h}+\gamma_{s, h}+\phi_{t, h}+\varepsilon_{s, t, h}$, where $\beta_{h}^{\text {big }}$ and $\beta_{h}^{\text {small }}$ are the tax-changesize-specific coefficients. We report the series based on the $\beta_{h}^{b i g}$ coefficients. In all series, capital gains are in real terms, and the estimated coefficients are normalized to equal 0 at time -1, i.e., we plot $\hat{\delta}_{h}$ as described in section 2.1. Standard errors are clustered at the state level. 
Figure 3: Migration Effects of State Capital Gains Taxes and Policy-Relevant Elasticity Estimates

(a) Residents in top $10 \%$ of national wealth distribution

(b) Residents in top $1 \%$ of national wealth distribution
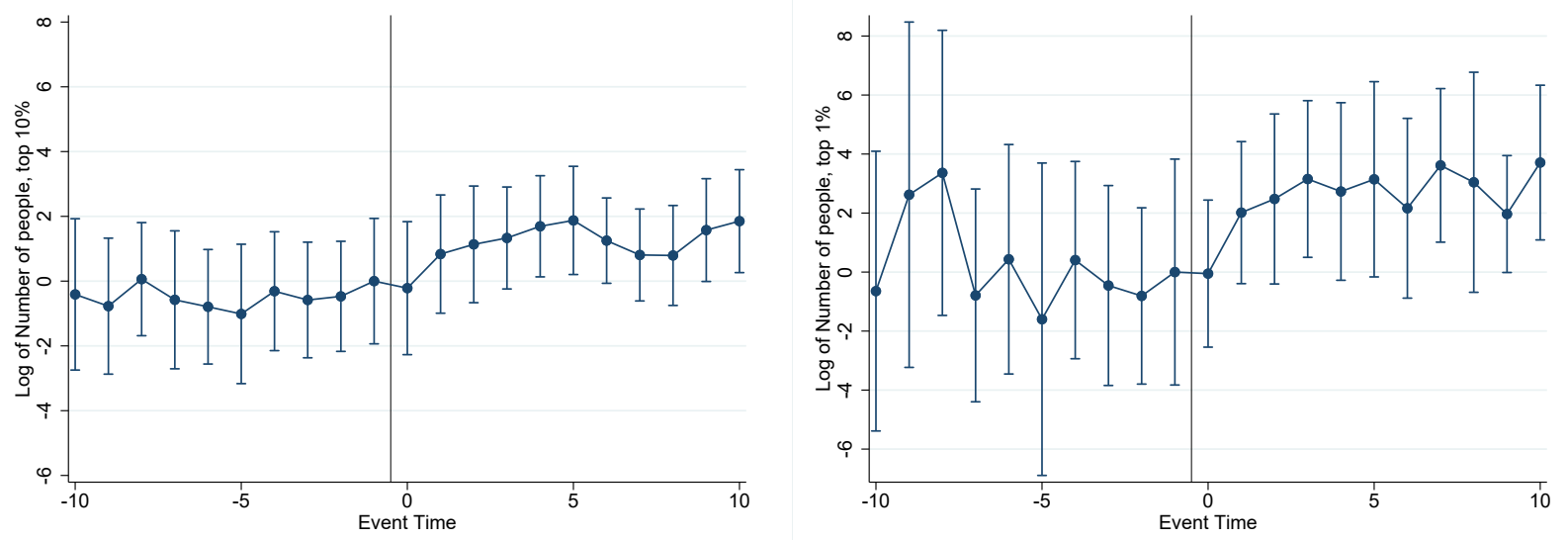

(c) Binned estimates of empirical and policy-relevant elasticities

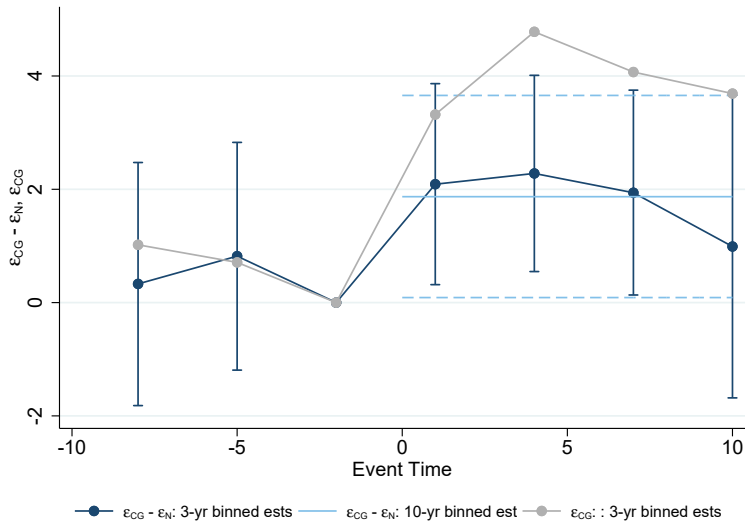

Notes: Panels (a) and (b) of this figure show the impact of state capital gains tax reforms on migration of high-net worth residents, using the specification in equation (1). The outcome in panel (a) is the log of the share of residents belonging to the top 10 percent of the national wealth distribution, and in panel (b) it is the log share in the top 1 percent. The points plotted are the estimated coefficients for the impact of a one-period change in the total (federal and state) log net-of-tax capital gains tax rate on these outcome variables. In panel (c), we estimate the empirical capital gains elasticity using a specification analogous to that in equation (1), but using three-year bins (see section 2.2 for details). This estimate is represented by the grey point estimates. The dark blue point estimates represent our estimates of the policy-relevant elasticity $\hat{\varepsilon}^{R}=\hat{\varepsilon}^{C G}-\hat{\varepsilon}^{N}$ for each period. As described in section 2.2, $\hat{\varepsilon}^{N}$ is estimated using a state-year specific dollar-weighted average of the migration responses of the top $1 \%$ and top $10 \%$. The horizontal light-blue line is our estimate of the policy-relevant elasticity using a binned specification for post-reform years 0-10 (see equation 3). All specifications include state and year fixed effects and controls for tax reforms in years surrounding the reform. The estimated coefficients are normalized to equal 0 at time -1 , and standard errors are clustered at the state level. 
Table 1: Summary Statistics on State Capital Gains Realizations and Tax Rates

\begin{tabular}{|c|c|c|c|c|c|}
\hline & Observations & Mean & $\begin{array}{l}\text { Standard } \\
\text { deviation }\end{array}$ & Minimum & Maximum \\
\hline \multicolumn{6}{|l|}{ Capital gains realizations } \\
\hline Capital gains income $(\$ B)$ & 1887 & 9.33 & 16.50 & 0.19 & 176.12 \\
\hline Log capital gains income & 1887 & 15.25 & 1.22 & 12.14 & 18.99 \\
\hline Per capita capital gains income $(\$ 1000$ s) & 1887 & 1.58 & 1.21 & 0.18 & 20.12 \\
\hline \multicolumn{6}{|l|}{ Tax variables } \\
\hline State capital gains tax rate $\left(\tau_{s t}^{\text {state }}\right)$ & 2091 & 0.04 & 0.03 & 0.00 & 0.15 \\
\hline Keep rate & 2091 & 0.75 & 0.05 & 0.63 & 0.85 \\
\hline Log keep rate & 2091 & -0.29 & 0.07 & -0.46 & -0.16 \\
\hline Indicator for $\Delta \tau_{\text {st }}^{\text {state }} \neq 0$ & 2040 & 0.29 & 0.45 & 0.00 & 1.00 \\
\hline$\Delta \tau_{\text {st }}^{\text {state }}$ if $\Delta \tau_{\text {st }}^{\text {state }} \neq 0$ & 584 & 0.00 & 0.01 & -0.08 & 0.09 \\
\hline Indicator for $\Delta \tau_{s t}^{\text {state }} \geq 0.01$ & 2040 & 0.04 & 0.19 & 0.00 & 1.00 \\
\hline$\Delta \tau_{\text {st }}^{\text {state }}$ if $\Delta \tau_{\text {st }}^{\text {state }} \geq 0.01$ & 75 & 0.03 & 0.02 & 0.01 & 0.09 \\
\hline Indicator for $\Delta \tau_{\text {st }}^{\text {state }} \leq-0.01$ & 2040 & 0.03 & 0.16 & 0.00 & 1.00 \\
\hline$\Delta \tau_{\text {st }}^{\text {state }}$ if $\Delta \tau_{\text {st }}^{\text {state }} \leq-0.01$ & 53 & -0.02 & 0.01 & -0.08 & -0.01 \\
\hline
\end{tabular}

Notes: This table summarizes capital gains and tax variables used in our analysis, which are observed at the state-year level. We report counts and magnitudes for changes in state capital gains tax changes in three bins: non-zero changes, increases of one percentage point or more, and decreases of one percentage point or more. The sample ranges from 1980 to 2016 for realizations, and from 1977 to 2017 for tax rates. All dollar values are in 2018 dollars. We use capital gains income data from Smith, Zidar and Zwick (2020) and data on state population from the Census Bureau via FRED. Data on state and federal capital gains tax rates are from NBER TAXSIM. Keep rates $\left(1-\tau_{s t}\right)$ are net of federal and state taxes on capital gains, accounting for deductibility and other provisions described in section 1 . See data appendix $\mathrm{B}$ for additional details. 
Table 2: Capital Gains Elasticities and Revenue-Maximizing Tax Rates

\begin{tabular}{|c|c|c|c|c|c|}
\hline$\underline{\text { Specification }}$ & $\begin{array}{l}\text { Total elasticity, } \\
\varepsilon^{C G}\end{array}$ & $\begin{array}{l}\text { Policy elasticity, } \\
\varepsilon^{R}=\varepsilon^{C G}-\varepsilon^{N}\end{array}$ & $\begin{array}{l}\text { Laffer rate, } \\
\tau^{*}=\frac{1-\bar{\tau}_{S}}{1+\varepsilon^{R}}\end{array}$ & $\begin{array}{l}\text { Elasticity with } \\
\text { respect to tax } \\
\varepsilon^{t a x}=\varepsilon^{R} \cdot \frac{-0.22}{1-0.22}\end{array}$ & $\begin{array}{r}\chi^{2} \text { test: } \\
\varepsilon^{\text {tax }}=-1\end{array}$ \\
\hline \multicolumn{6}{|l|}{ Baseline } \\
\hline $0-10$ years & 3.39 & 1.87 & 0.33 & -0.53 & 3.38 \\
\hline & (1.01) & (0.91) & $(0.10)$ & $(0.26)$ & $(0.07)$ \\
\hline \multirow[t]{2}{*}{0 - 2 years } & 3.32 & 2.09 & 0.30 & -0.59 & 2.58 \\
\hline & $(0.97)$ & $(0.91)$ & (0.09) & $(0.26)$ & $(0.11)$ \\
\hline \multirow[t]{2}{*}{ 3-5 years } & 4.78 & 2.28 & 0.29 & -0.64 & 2.05 \\
\hline & $(1.10)$ & $(0.88)$ & $(0.08)$ & $(0.25)$ & $(0.15)$ \\
\hline \multirow[t]{2}{*}{$6-8$ years } & 4.07 & 1.94 & 0.32 & -0.55 & 3.02 \\
\hline & $(1.20)$ & $(0.92)$ & $(0.10)$ & $(0.26)$ & $(0.08)$ \\
\hline \multirow[t]{2}{*}{$6-10$ years } & 3.66 & 1.47 & 0.38 & -0.41 & 4.54 \\
\hline & $(1.27)$ & $(0.97)$ & $(0.15)$ & $(0.27)$ & $(0.03)$ \\
\hline \multicolumn{6}{|l|}{ Big changes only } \\
\hline \multirow[t]{2}{*}{ 0-10 years } & 2.81 & 1.48 & 0.38 & -0.42 & 5.31 \\
\hline & $(1.02)$ & (0.89) & $(0.14)$ & $(0.25)$ & $(0.02)$ \\
\hline \multirow[t]{2}{*}{0 - 2 years } & 3.54 & 2.50 & 0.27 & -0.71 & 1.14 \\
\hline & $(0.97)$ & $(0.98)$ & $(0.07)$ & $(0.28)$ & $(0.29)$ \\
\hline \multirow[t]{2}{*}{ 3-5 years } & 4.96 & 2.40 & 0.28 & -0.68 & 1.54 \\
\hline & (1.10) & $(0.92)$ & $(0.07)$ & $(0.26)$ & $(0.21)$ \\
\hline \multirow{2}{*}{$6-8$ years } & 3.77 & 1.65 & 0.35 & -0.46 & 4.35 \\
\hline & (1.19) & $(0.91)$ & $(0.12)$ & $(0.26)$ & $(0.04)$ \\
\hline \multirow[t]{2}{*}{$6-10$ years } & 2.80 & 0.99 & 0.47 & -0.28 & 6.48 \\
\hline & $(1.30)$ & $(1.00)$ & $(0.24)$ & $(0.28)$ & $(0.01)$ \\
\hline \multicolumn{6}{|l|}{ Control for other } \\
\hline \multirow[t]{2}{*}{$0-10$ years } & 2.28 & 1.01 & 0.47 & -0.29 & 4.64 \\
\hline & $(1.32)$ & (1.18) & $(0.27)$ & $(0.33)$ & $(0.03)$ \\
\hline \multirow[t]{2}{*}{$0-2$ years } & 2.38 & 1.25 & 0.42 & -0.35 & 3.88 \\
\hline & (1.19) & $(1.16)$ & $(0.21)$ & $(0.33)$ & $(0.05)$ \\
\hline \multirow[t]{2}{*}{ 3-5 years } & 3.58 & 1.64 & 0.36 & -0.46 & 3.54 \\
\hline & $(1.24)$ & $(1.01)$ & $(0.14)$ & $(0.29)$ & $(0.06)$ \\
\hline \multirow[t]{2}{*}{$6-8$ years } & 3.32 & 1.40 & 0.39 & -0.39 & 3.57 \\
\hline & (1.43) & (1.14) & $(0.19)$ & $(0.32)$ & $(0.06)$ \\
\hline \multirow{2}{*}{$6-10$ years } & 2.98 & 1.18 & 0.43 & -0.33 & 3.96 \\
\hline & $(1.54)$ & (1.19) & $(0.24)$ & $(0.34)$ & $(0.05)$ \\
\hline
\end{tabular}

Notes: This table shows estimates of main elasticities and associated revenue-maximizing rate for different specifications of equation (2). The 0-2, 3-5 and 6-8 year specifications use 3-year bins, the 6-10 year specification uses a 5-year bin, and the 0-10 year specification uses an 11-year bin as described by equation (3)). As described in the main text, the empirical elasticities $\hat{\varepsilon}^{C G}$ and $\hat{\varepsilon}^{N}$ are calculated as the difference between the point estimate for each specific horizon, and the point estimate for the $[-3,-1]$-year bin. Revenue-maximizing tax rates are estimated using the formula in equation (6), which is derived in Online Appendix Section E. The term $\bar{\tau}_{S}$ adjusts for the average population-weighted state tax rate in 2016, which was $6.27 \%$ in 2016 . All specifications control for reforms in the capital gains tax rate in three 3-year bins before and after the reform in question, and include state and year fixed effects. The "Big changes only" specification replaces the right hand side variable of interest-the 3-year (or 5-year or 11-year) change in the log net-of-tax rate-with two variables: one which sums the changes in the log net-of-tax rate in years where the state tax rate changed by more than 1 percentage point, leaving out smaller changes, and one which sums changes to the log net-of-tax rate in years where the state rate changed by less than 1 percentage point. Specifically, we replace the right-hand side variable of interest - for instance, $\Delta_{3} \log \left(1-\tau_{s, t}\right)$ - with two variables: $\Delta_{3}^{\text {big }} \log \left(1-\tau_{s, t}\right) \equiv \sum_{k=0}^{2} \Delta \log \left(1-\tau_{s, t-k}\right) \times \mathbf{1}\left(\left|\Delta\left(1-\tau_{s, t-k}\right)\right| \geq\right.$ $0.01)$, which sums all the tax changes greater than 1 percentage point in magnitude over the past year, and a corresponding variable that sums all tax changes smaller than 1 percentage point. We then report estimates for the variable that sums the big changes.

The "Control for other taxes" rows report results from a specification that includes controls for changes in state income and corporate tax rates. We control for the change in other tax taxes over the same 3-year (or 5-year or 11-year) bins that we use to identify our main point estimate in each regression, as well as three 3-year bins before and after the main period. Standard errors are clustered at the state level. Values in parentheses in columns 1-4 represent standard errors; values in parentheses in column 5 ( $\chi^{2}$ test) represent p-values. 


\section{Appendix For Online Publication}

\section{A Appendix Figures}

Figure A.1: Estimates from the Capital Gains Literature

(a) Elasticities

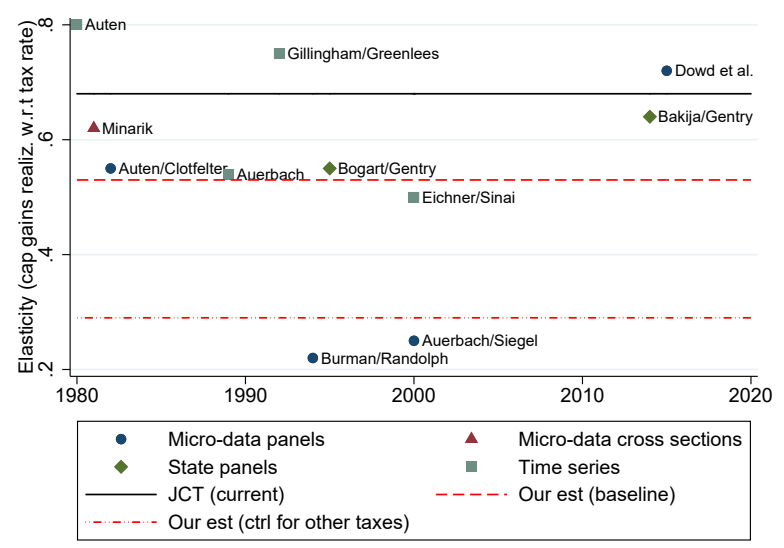

(b) Revenue from 5 pp tax increase

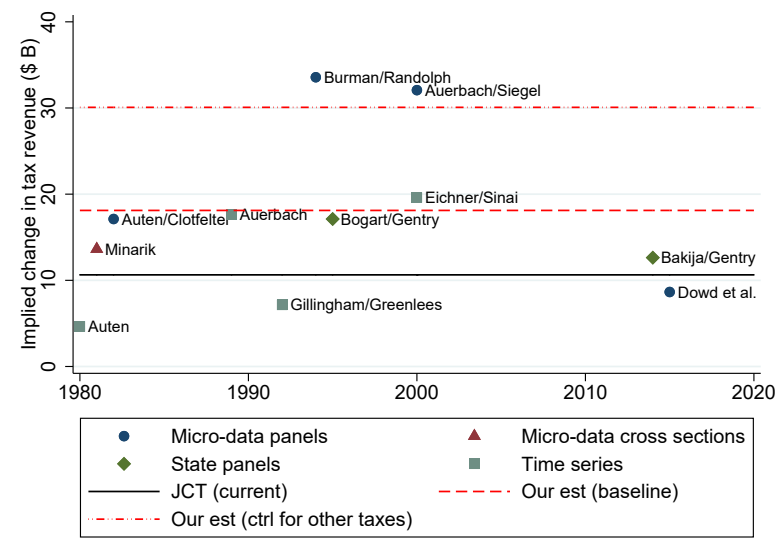

(c) Revenue-maximizing tax rate

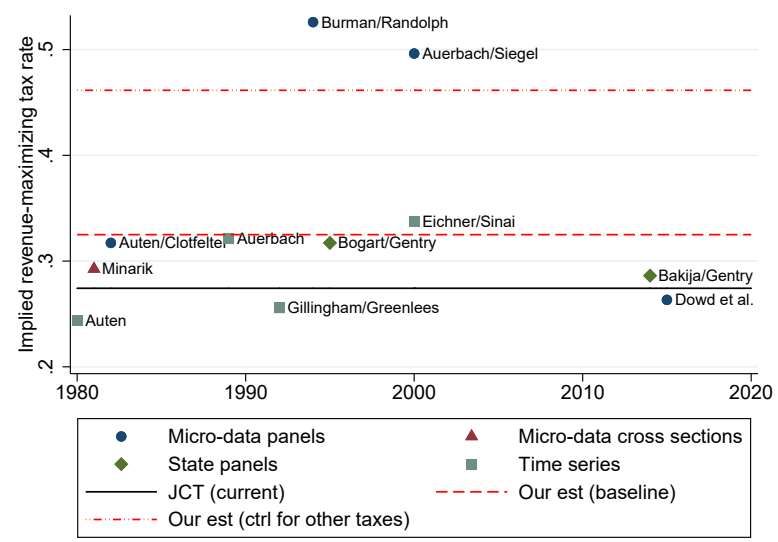

Notes: This figure compares our results with those from the previous literature on capital gains. With the exception of Dowd, McClelland and Muthitacharoen (2015), the elasticities reported in panel (a) are calculated with respect to a tax rate of $22 \%$ and are taken from Tables 1 and B-1 from Gravelle (2020). The relevant marginal tax rates in the Dowd et al. paper are those in place between 1999 and 2008, which average around 17 percent. The tax increase analyzed in panel (b) is a 5 percentage point increase, from $17.8 \%$ (the effective federal capital gains tax rate in 2018 ) to $22.8 \%$, assuming that realizations and revenues begin at their 2018 levels ( $\$ 891 \mathrm{~B}$ and $\$ 158 \mathrm{~B}$ respectively). We calculate revenue-maximizing rate using equation (6) from the text, using an average state tax rate of $6.4 \%$ (its 2016 population-weighted value). 
Figure A.2: Histogram of State Capital Gains Tax Rate Changes

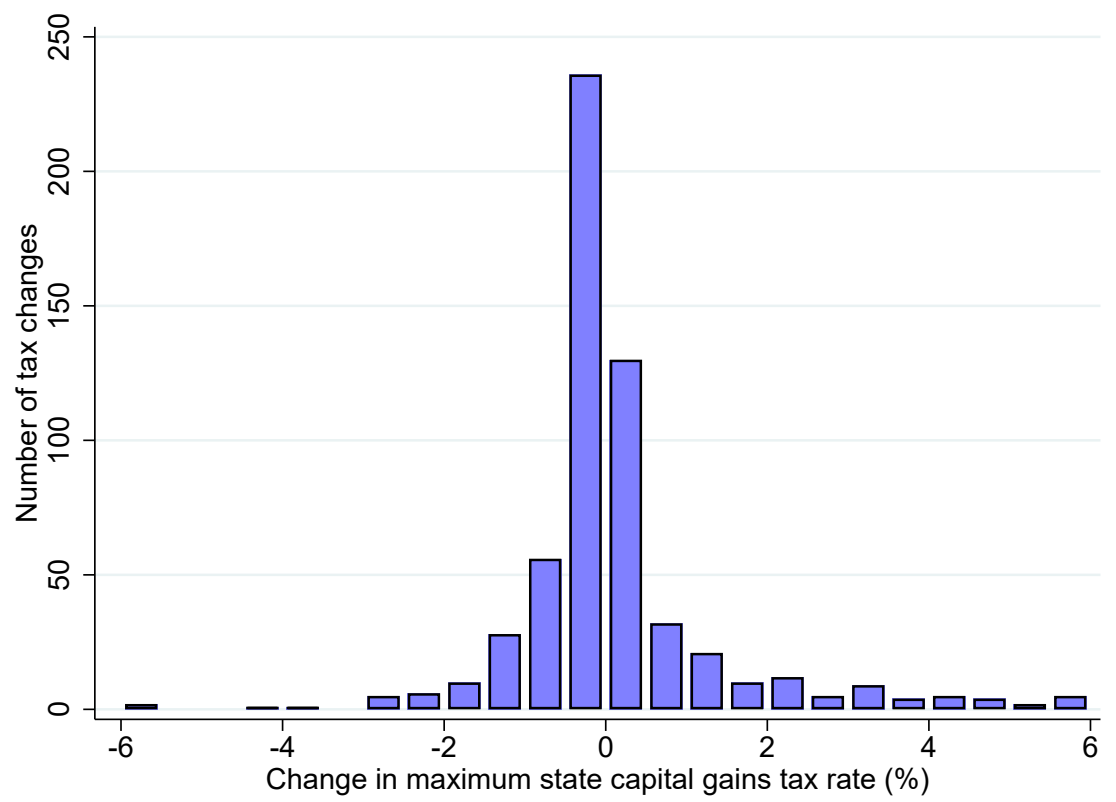

Notes: This figure shows the distribution of the size of changes in the top state capital gains tax rate throughout our panel, including changes to the statutory tax rate as well as deductibility and other minor provisions of the tax code. It has been censored at $6 \%$, so tax changes of more than 6 percentage points in absolute value appear in the left- or rightmost bin in this figure. The figure does not include state-years where the tax rate stayed the same, i.e. changed by 0 .

Figure A.3: Long- and short-term share of capital gains

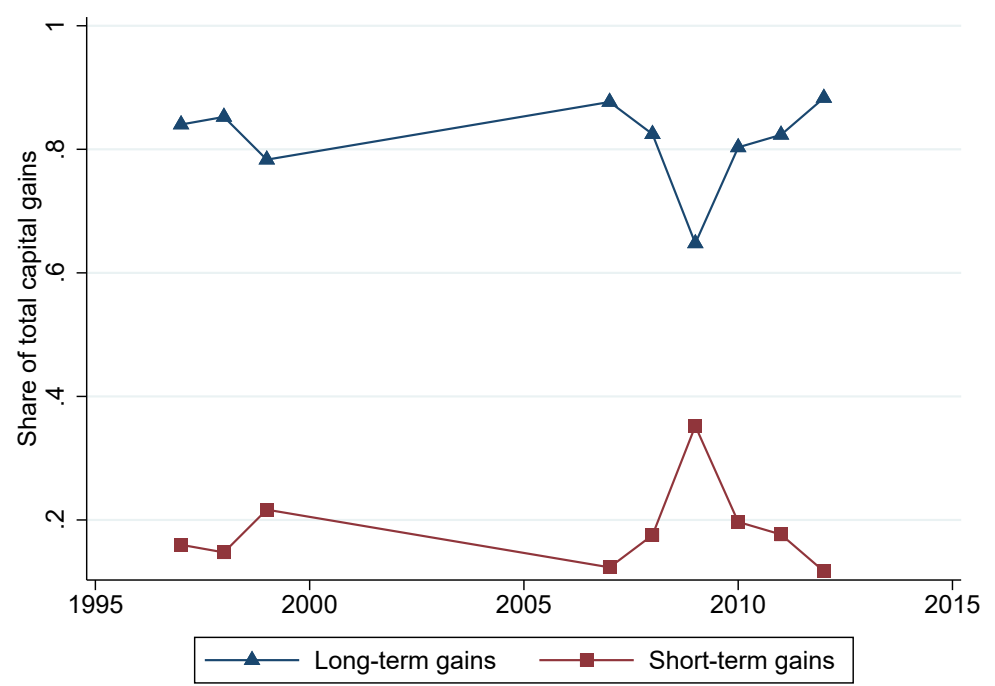

Notes: Data from the IRS SOI series "Short-term and Long-term Capital Gains and Losses" classified by size of adjusted gross income and selected asset type (accessible at https://www.irs.gov/statistics/ soi-tax-stats-sales-of-capital-assets-reported-on-individual-tax-returns). More precisely, the long-term gain series corresponds to total gains reported in returns with long-term gain transactions. The short-term gain series corresponds to total gains reported in returns with short-term gain transactions. We calculate total capital gains as the sum of these two series. We use cross-sectional data, which are available for 1985, 1997-1999, and 2007-2012. Although panel data are available for 1999-2007, the IRS warns that extrapolations from the panel to the general population should be made with "extreme caution". Due to the IRS' warning, we have omitted data for these years. 
Figure A.4: The Effect of Net-of-Tax Rate Changes on the Net-of-Tax Rate over Time

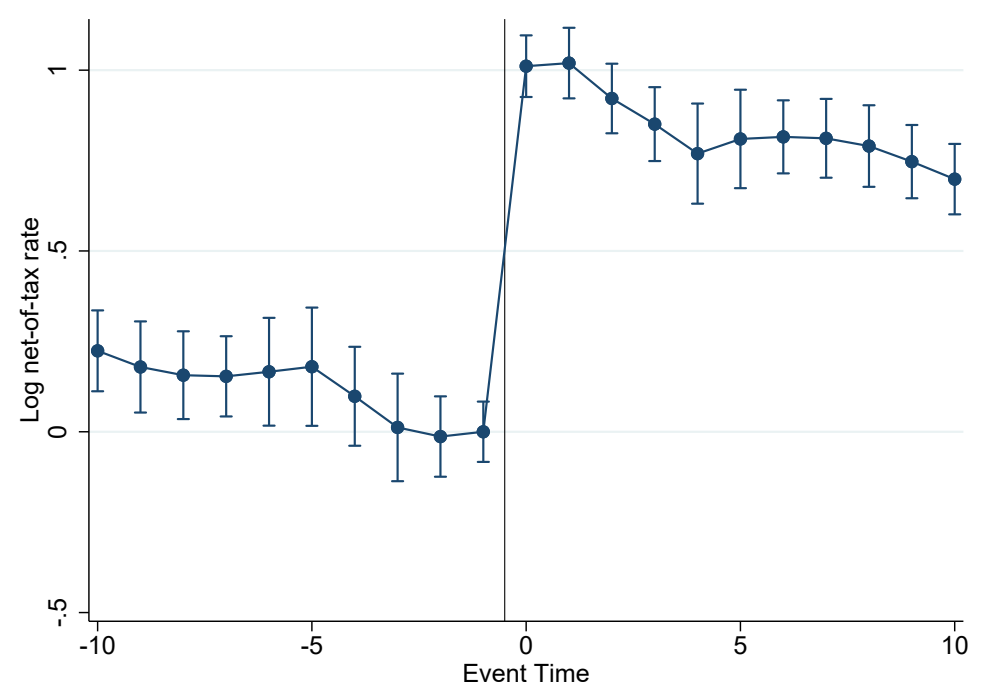

Notes: This figure uses our direct projections framework from equation (1), but with the outcome variable being the net-oftax rate itself, and excluding the controls for capital gains tax reforms in other years. This creates a specification where the treatment effect from time -1 to time 0 is 1 by construction, but where the point estimates in other years show the degree of mean reversion in tax rates. A decline in point estimates following the initial jump indicates mean reversion, as states that lower tax rates tend to partially revert back towards higher tax rates over time and vice versa. The estimated coefficients are normalized to equal 0 at time -1 . Standard errors are clustered at the state level. 
Figure A.5: Scatterplots, 3-year Changes in Log Capital Gains, Net-of-Tax Rate, and Log Net-of-Tax Rate

(a) Log capital gains and net-of-tax rate

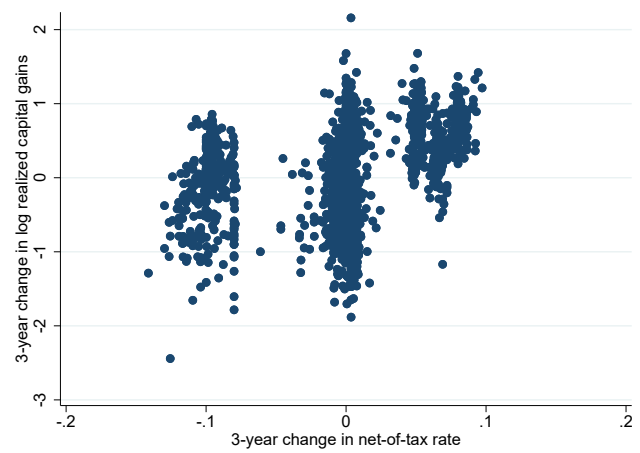

(c) Binscatter, log capital gains and net-of-tax rate

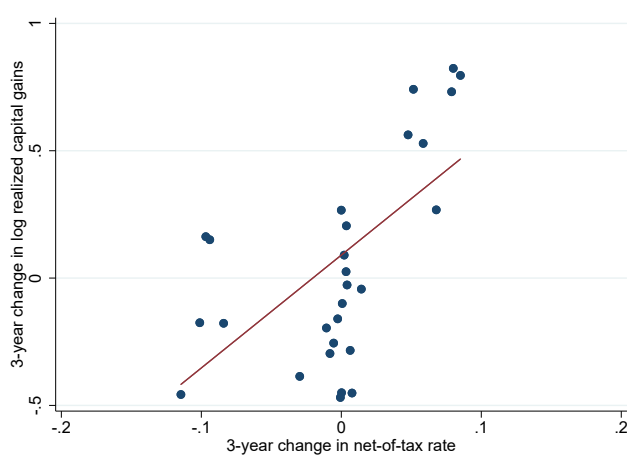

(b) Log capital gains and log net-of-tax rate

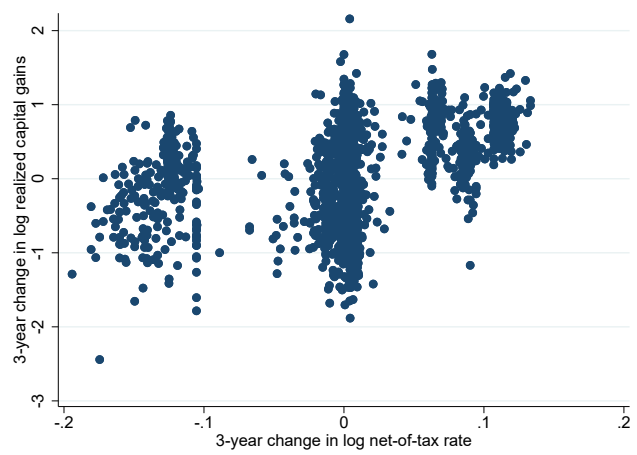

(d) Binscatter, log capital gains and log net-oftax rate

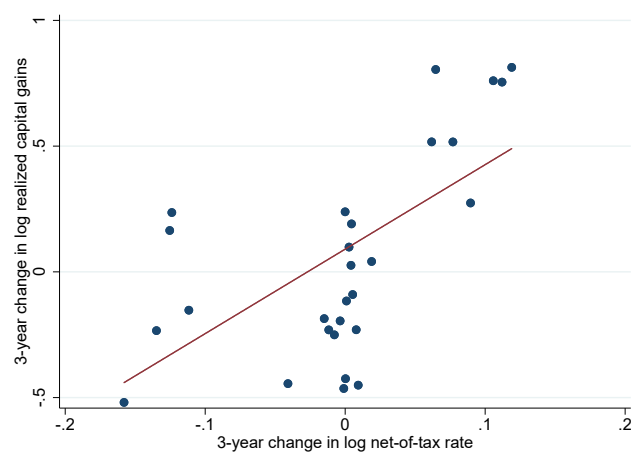

Notes: This figure shows two scatterplots of our state-year data on tax rates and realized capital gains, as well as corresponding binned scatterplots. In all plots, the variable on the vertical axis is the three-year change in log realized capital gains (2018 dollars). In the plots on the left, the variable on the horizontal axis is the three-year change in the net-of-tax rate by state (using the maximum combined federal and state capital gains tax rate, as we describe in section 1.), while in the plots on the right, the horizontal axis shows the three-year change in the log net-of-tax rate. The plots in the top row are standard scatterplots, while the plots in the bottom row are the corresponding binned scatter plots, using 30 bins. The regression corresponding to the line of best fit in the scatterplot in panel (c) has an $R^{2}$ of 0.1304 , and in panel (b) the $R^{2}$ is 0.1352 . 
Figure A.6: Comparing Elasticity Assumptions

(a) Elasticities

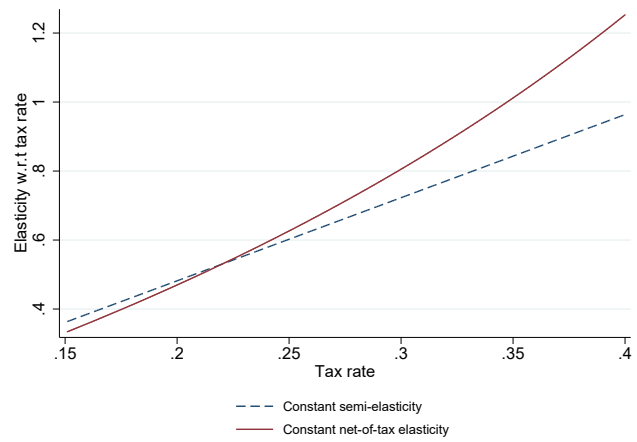

(b) Realizations

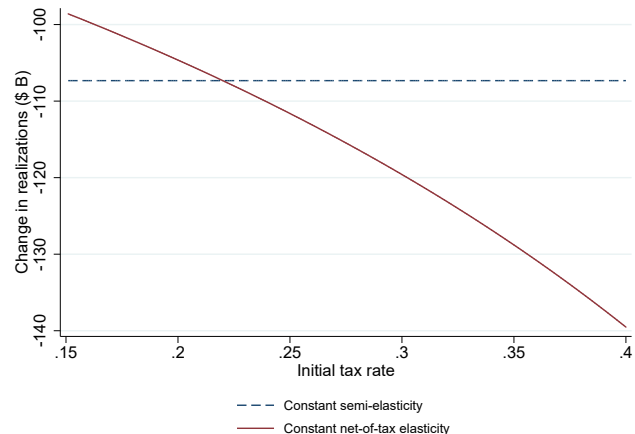

(c) Revenues

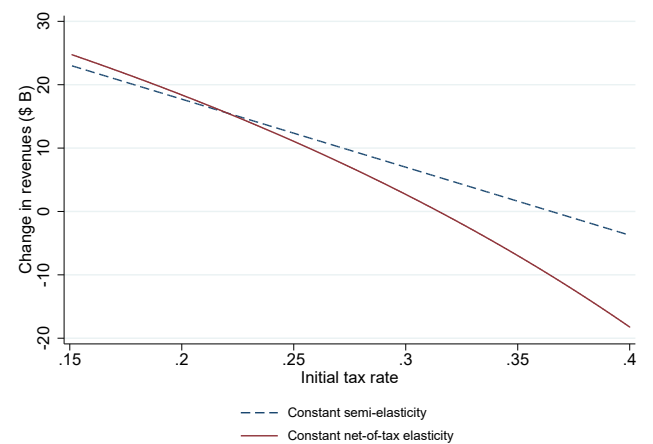

Notes: This figure supplements the discussion in section 2.1 of models of capital gains realizations that either assume a constant semi-elasticity (models of the form $\log C G_{t}=\gamma \cdot \tau_{t}$ ), or a constant net-of-tax elasticity (of the form $\log C G_{t}=$ $\left.\delta \cdot \log \left(1-\tau_{t}\right)\right)$. We here show some implications of these models at various tax rates when either the semi-elasticity or the netof-tax elasticity is assumed to be constant for all tax rates. All calculations are based on a tax rate elasticity of 0.53 at $22 \%$, corresponding to a semi-elasticity of 2.41 and a net-of-tax rate elasticity of 1.88 . Panel (a) shows, at each given tax rate, what is obtained when converting the semi-elasticity or net-of-tax elasticity to an elasticity with respect to the tax rate. We also evaluate the implications of both models for realizations (panel b) and tax revenue (panel c) under a 5 percentage point tax increase relative to the tax rate on the horizontal axis. We assume initial realizations equal to $\$ 891$ billion regardless of starting tax rate. This figure is equal to net capital gains realizations in 2018 according to data from Piketty, Saez and Zucman (2018). Total tax rates observed in our data range from 0.15 to 0.37 , comparable to the range of rates presented here. 
Figure A.7: The Effect of Net-of-Tax Rate Changes on Capital Gains Realizations, by Specification

(a) Control for GDP

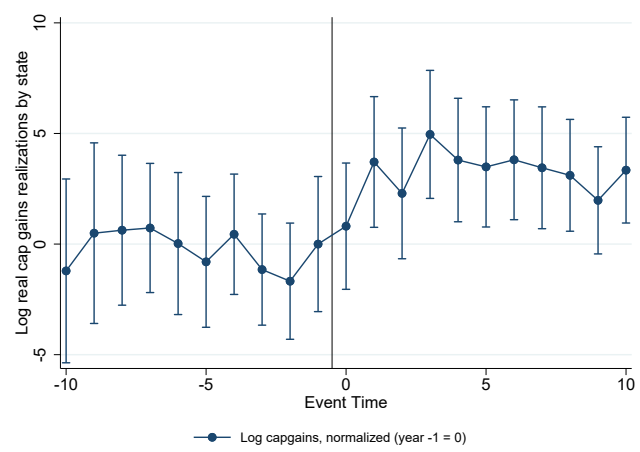

(c) Control for unemployment

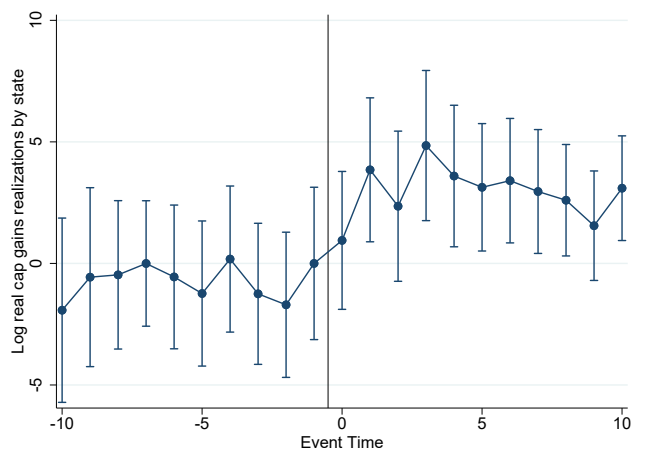

(b) Control for GDP growth*year

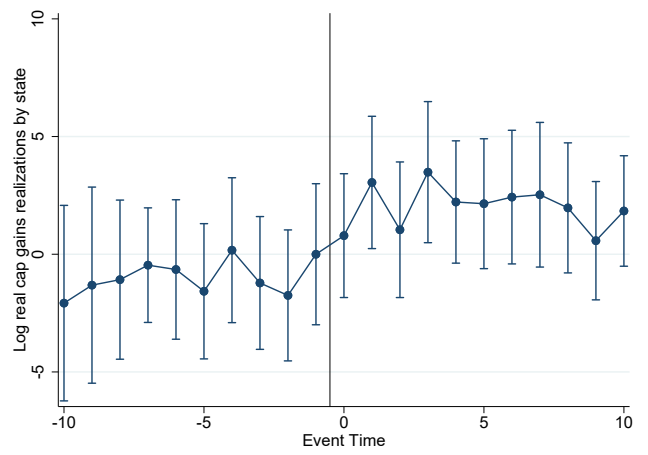

(d) Large reforms only

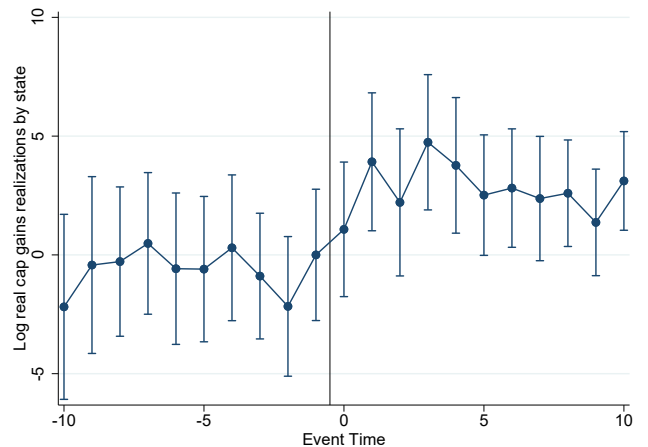

(e) Control for other taxes

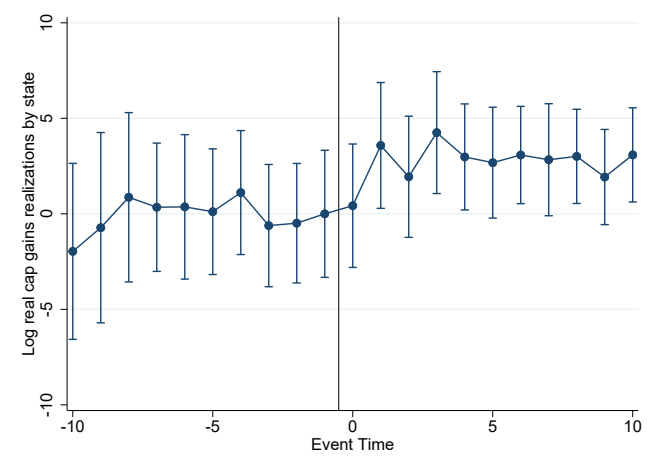

Notes: This figure shows the five series from panel (b) of Figure 2 individually. Panel (a) in this figure controls linearly for GDP in the year before the reform; panel (b) controls for a set of dummies interacting GDP growth tertiles and years, where the GDP growth tertile is determined separately in each year by grouping states according to GDP growth over the three years prior to the reform; panel (c) controls for the unemployment rate in the year prior to the capital gains tax reform. Panel (d) uses a specification that interacts the variable for changes in the net-of-tax rate with indicators for reforms greater or smaller than 1 percentage point in magnitude - the reported point estimates are for the interaction with the large reform dummy, such that the effects shown in this panel are idetified only from larger reforms. Panel (e) includes controls for changes in the state personal income and corporate tax rates in each year from 10 years before until 10 years after the capital gains reform. In all cases, we plot the estimated coefficients for the impact of a one-period change in the total (federal and state) log net-of-tax capital gains tax rate on log capital gains realizations. Capital gains are in real terms and standard errors are clustered at the state level. Estimates have been normalized to 0 in period -1 . We include state and year fixed effects. 
Figure A.8: Baseline Specification as Event Study

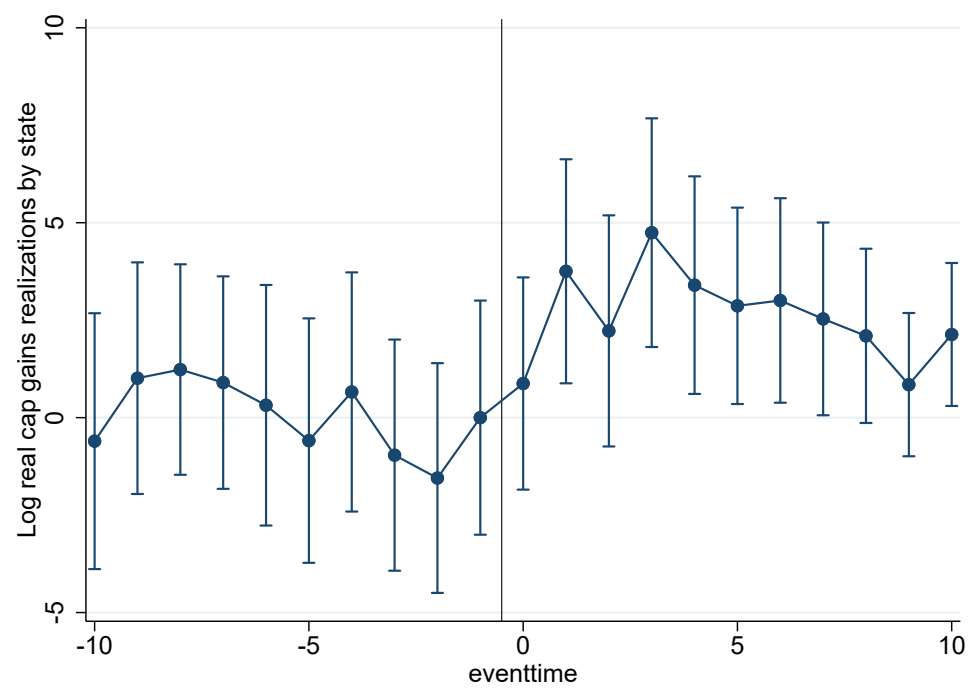

Notes: This figure shows a variation of our baseline graph in Figure 2 that uses a classic event study specification in which all plotted coefficients are estimated within the same single regression rather than the direct projections approach. The specification used is $y_{s, t}=\sum_{h=-10}^{10} \beta_{h} \Delta \log \left(1-\tau_{s, t-h}\right)+\gamma_{s}+\phi_{t}+\varepsilon_{s, t}$ (where $\Delta$ indicates a one-period change), and the figure plots the point estimates for $\beta_{-10}, \beta_{-9}, \ldots, \beta_{10}$. Capital gains are in real terms and the estimated coefficients are normalized to equal 0 at time -1 . Standard errors are clustered at the state level.

Figure A.9: The Effect of Net-of-Tax Rate Changes on Capital Gains Realizations - No Controls for Other Capital Gains Tax Reforms

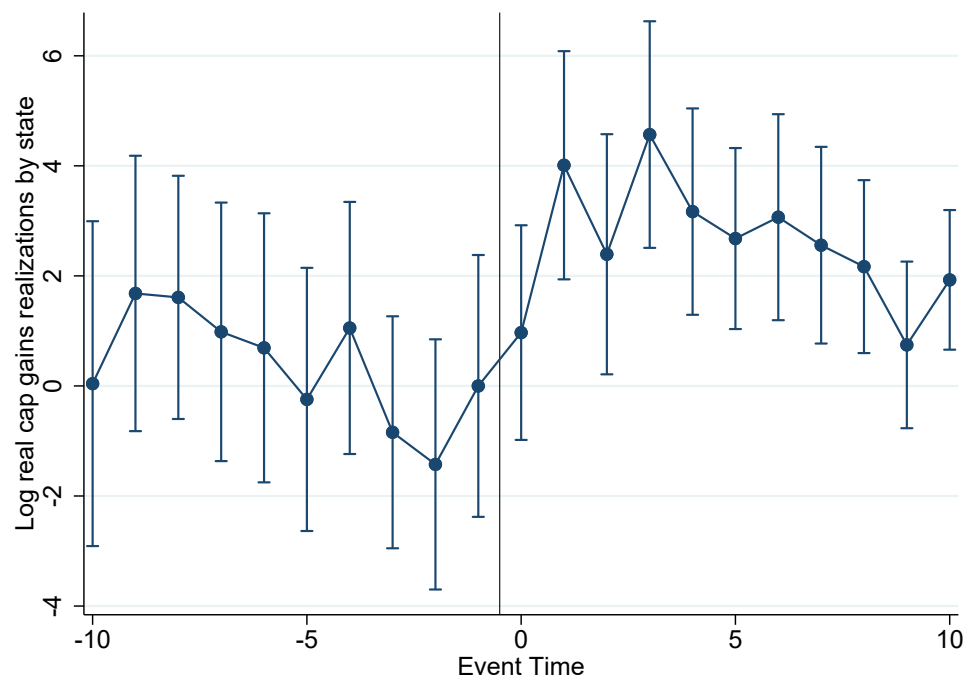

Notes: This figure is analogous to panel (a) of Figure 2, but without controls for other changes in the capital gains tax rate before and after the reform of interest. Realized capital gains are in real terms, and the estimated coefficients are normalized to equal 0 at time -1 . Standard errors are clustered at the state level. 
Figure A.10: The Effect of Net-of-Tax Rate Changes on Capital Gains Realizations - Tax Cuts and Increases

(a) Tax cuts only

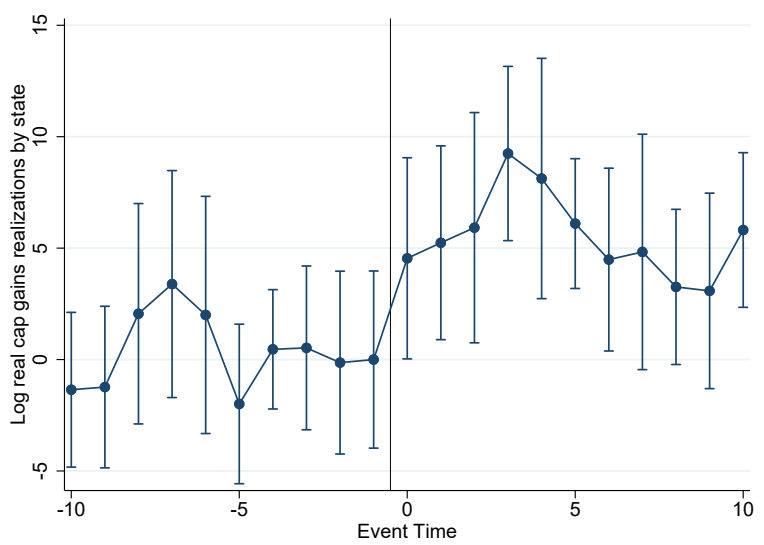

(b) Tax increases only

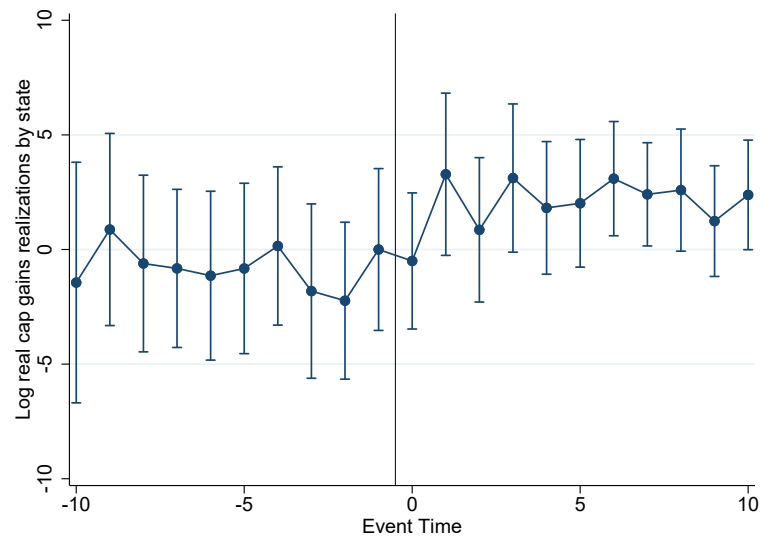

Notes: This figure is analogous to panel (a) of Figure 2, but shows the effects of tax cuts and tax increases separately. Specificatlly, we modify the baseline specification in equation (1) by estimating separate coefficients for tax increases and decreases, i.e., we use the specification $y_{s, t+h}=\beta_{h}^{\text {cut }} \times \mathbf{1}\left(\Delta \tau_{s, t}<0\right) \times \Delta \log \left(1-\tau_{s, t}\right)+\beta_{h}^{\text {inc }} \times \mathbf{1}\left(\Delta \tau_{s, t}>0\right) \times \Delta \log \left(1-\tau_{s, t}\right)+\mathbf{X}_{s, t}^{\prime} \boldsymbol{\Lambda}_{h}+$ $\gamma_{s, h}+\phi_{t, h}+\varepsilon_{s, t, h}$, where $\mathbf{1}\left(\Delta \tau_{s, t}<0\right)$ is an indicator for tax cuts, $\mathbf{1}\left(\Delta \tau_{s, t}>0\right)$ is an indicator for tax increases, and $\beta_{h}^{\text {cut }}$ and $\beta_{h}^{i n c}$ are the corresponding tax-change-direction-specific coefficients. Panel (a) reports the coeffcients $\left\{\beta_{h}^{c u t}\right\}_{h=-10}^{10}$, and panel (b) reports $\left\{\beta_{h}^{i n c}\right\}_{h=-10}^{10}$ from this specification. Realized capital gains are in real terms, and the estimated coefficients are normalized to equal 0 at time -1 . Standard errors are clustered at the state level.

Figure A.11: The Effect of Net-of-Tax Rate Changes on Capital Gains Realizations in the 10 most populous states versus the rest

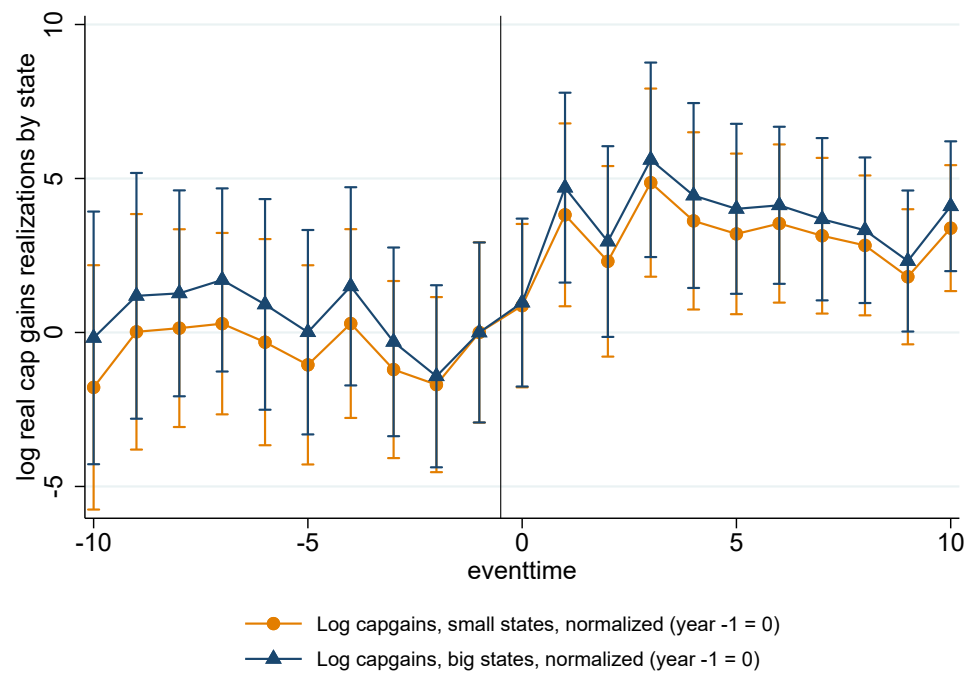

Notes: This figure is analogous to panel (a) of Figure 2, but interacts the main right-hand-side variable of interest with an indicator for belonging to the 10 most populous states, lagged by 10 years relative to the reform to avoid any potential confounding effects of recent population growth or decline. This thus creates two sets of treatment effects, one for larger and one for smaller states. Realized capital gains are in real terms, and the estimated coefficients are normalized to equal 0 at time -1 . Standard errors are clustered at the state level. 
Figure A.12: The Effect of Net-of-Tax Rate Changes on Capital Gains Realizations After 1990

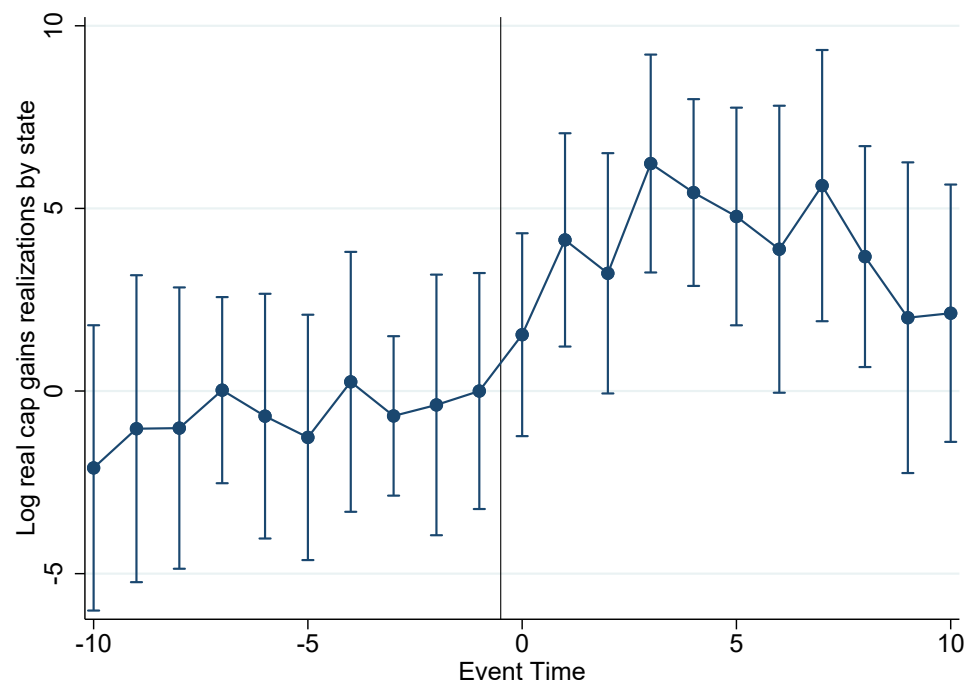

Notes: This figure is analogous to panel (a) of Figure 2, but restricts the specification to only estimate the effects of reforms after 1990. We do use realizations data from prior to 1990 to estimate the pre-trend, and we also include reforms from before 1990 when in our set of controls for capital gains tax reforms in the years surrounding the reform of interest. Realized capital gains are in real terms, and the estimated coefficients are normalized to equal 0 at time -1 . Standard errors are clustered at the state level.

Figure A.13: Binned Elasticity Estimates, Event Study Specification

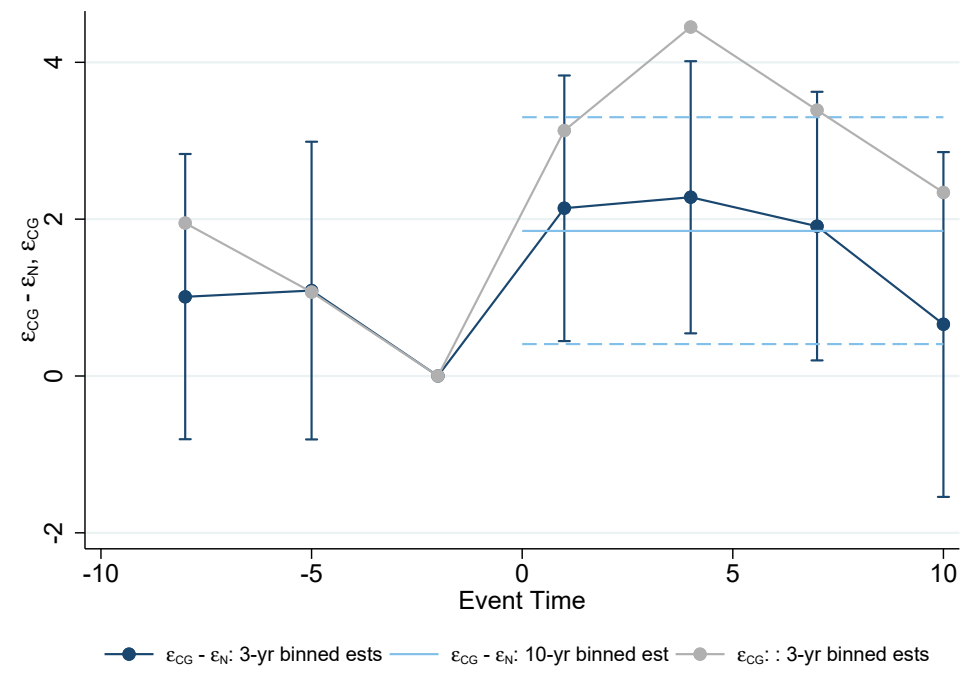

Notes: This figure is analogous to panel (c) of Figure 3, but uses an event study specification where elasticities at different horizons are estimated jointly within the same regression model rather than using separate regressions for each coefficient as in the direct projections case. Specifically, for the three-year bins, instead of equation (2), we run a single regression of the form $y_{s, t}=\beta_{-9} \Delta_{3} \log \left(1-\tau_{s, t+9}\right)+\beta_{-6} \Delta_{3} \log \left(1-\tau_{s, t+6}\right)+\cdots+\beta_{9} \Delta_{3} \log \left(1-\tau_{s, t-9}\right)+\gamma_{s}+\phi_{t}+\varepsilon_{s, t}$. Using capital gains realizations as the outcome variable, the grey line then plots elasticity estimates $\hat{\varepsilon}^{C G}$ as the difference between the coefficients $\beta_{t}-\beta-3$ from this regression. Migration elasticities $\hat{\varepsilon}^{N}$ are calculated correspondingly, using our migration variable from the main text as the outcome variable, and the dark blue line then plots the estimated policy-relevant elasticity, $\hat{\varepsilon}^{R}=\hat{\varepsilon}^{C G}-\hat{\varepsilon}^{N}$. For the estimates in the 0-10 year bin, we run a separate regression $y_{s, t}=\tilde{\beta}_{-9} \Delta_{3} \log \left(1-\tau_{s, t+9}\right)+\tilde{\beta}_{-6} \Delta_{3} \log \left(1-\tau_{s, t+6}\right)+\tilde{\beta}_{-3} \Delta_{3} \log \left(1-\tau_{s, t+3}\right)+$ $\tilde{\beta}_{0} \Delta_{11} \log \left(1-\tau_{s, t}\right)+\tilde{\gamma}_{s}+\tilde{\phi}_{t}+\tilde{\varepsilon}_{s, t}$ and estimate the $0-10$ year elasticity as the difference $\tilde{\beta}_{0}-\tilde{\beta}_{-3}$. Standard errors are clustered at the state level. 
Figure A.14: Estimating Effects of Simulated Tax Changes Assuming a Constant Elasticity

(a) Direct projection, control for reforms in surrounding years

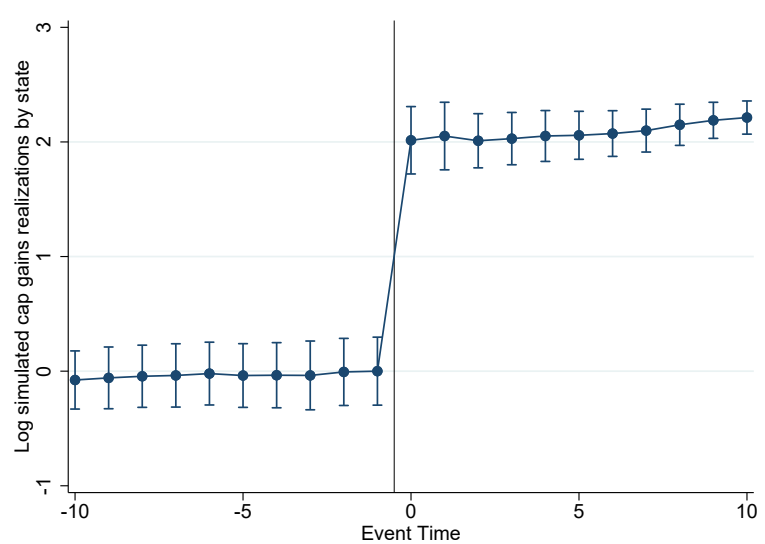

(b) Direct projection, no controls for other reforms

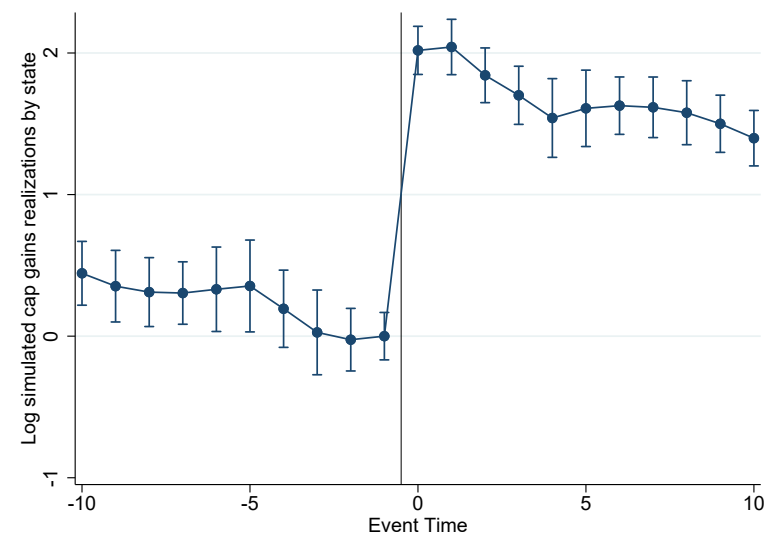

(c) Event study

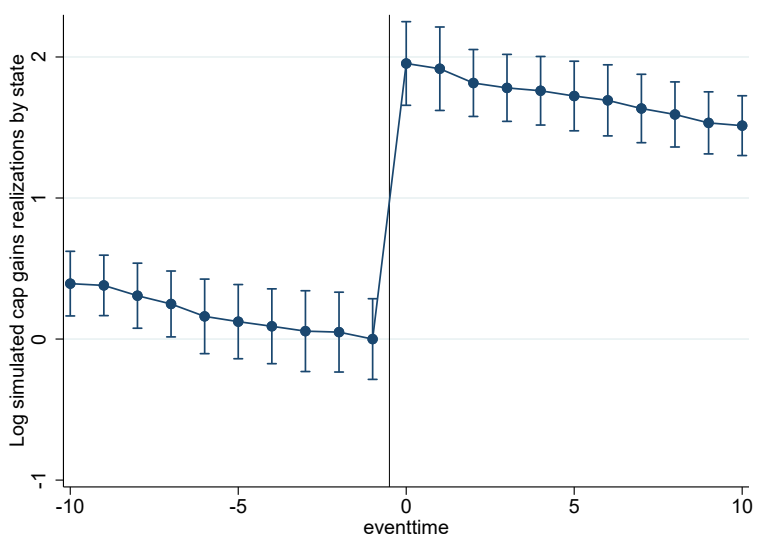

Notes: This figure shows the outcome of the simulation exercise detailed in Appendix Section D. We simulate a log capital gains realizations variable which is generated in such a way that it has a true empirical elasticity of 2 with respect to the net-oftax rate, constant across all horizons. The figures use three different methods to estimate the impact of changes in the net-oftax rate on this simulated outcome variable. Panel (a) shows the outcome of a direct projections estimation exactly as specified in equation (1), panel (b) shows the outcome of a similar specification that excludes the controls for tax reforms in other years, and panel (c) shows the outcome of an event study specification. Estimates have been normalized to 0 in period -1 . We include state and year fixed effects. See Appendix Section D for further details. 
Figure A.15: Estimating Effects of Simulated Tax Changes Assuming a Time-Varying Elasticity

(a) Direct projection, control for reforms in surrounding years

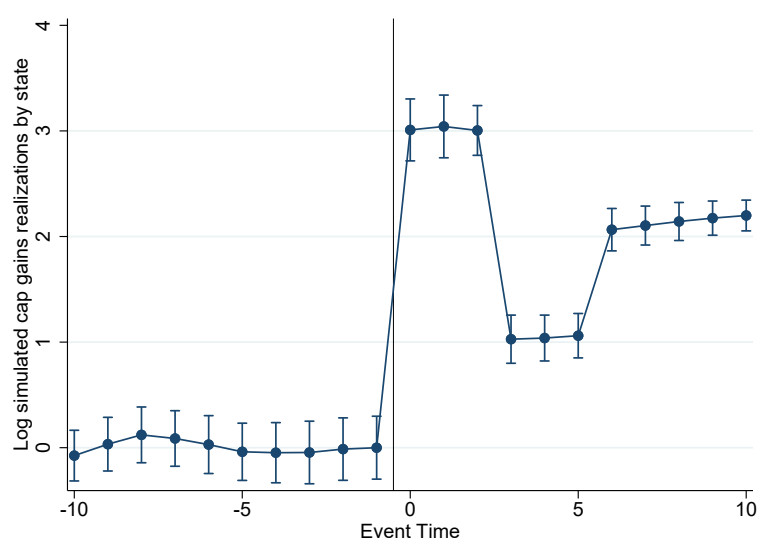

(b) 3-year and 10-year binned estimates

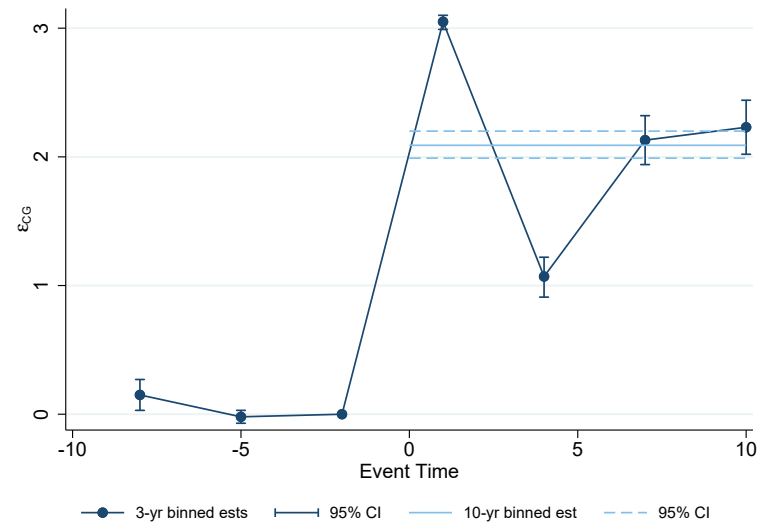

Notes: This figure shows the outcome of the simulation exercise detailed in Appendix Section D. Unlike Figure A.14, we here generate an outcome variable for which the true elasticity with respect to the net-of-tax rate is 3 in years $0-2$ following the reform, 1 in years 3-5, and 2 in the following years. Panel (a) shows the outcome of a direct projections estimation exactly as specified in equation (1). Panel (b) shows the outcome of the estimation when binned specifications as outlined in section 2.2 . We include state and year fixed effects. See Appendix Section D for further details. 
Table A.1: Largest Capital Gains Tax Changes by State-Year

\begin{tabular}{rrrrrr}
\hline & Year & $\begin{array}{c}\Delta \text { tax } \\
\text { rate }\end{array}$ & $\begin{array}{r}\text { Post-change } \\
\text { tax rate }\end{array}$ & $\begin{array}{c}\Delta \text { net of } \\
\text { tax rate }\end{array}$ & $\begin{array}{r}\text { Post-change } \\
\text { net tax rate }\end{array}$ \\
\cline { 2 - 6 } Largest tax decreases & & & & & \\
Oklahoma & 2005 & -7.97 & 0.19 & 5.19 & 83.83 \\
Alaska & 1980 & -5.80 & 0.00 & 1.79 & 72.79 \\
Rhode Island & 2003 & -4.46 & 4.82 & 2.67 & 75.82 \\
Montana & 2005 & -3.84 & 6.11 & 2.50 & 79.98 \\
New York & 1978 & -3.00 & 7.50 & 9.90 & 81.75 \\
Vermont & 2002 & -2.99 & 5.20 & 1.81 & 75.65 \\
Vermont & 1994 & -2.94 & 9.28 & 1.76 & 65.21 \\
Kansas & 1988 & -2.84 & 3.87 & 1.34 & 69.21 \\
Wisconsin & 1984 & -2.60 & 4.00 & 1.30 & 78.00 \\
North Carolina & 2014 & -2.18 & 5.80 & 1.27 & 71.73 \\
& & & & & \\
Largest tax increases & & & & & 65.88 \\
Maine & 1989 & 8.50 & 8.50 & -6.12 & 66.50 \\
Hawaii & 2016 & 7.30 & 14.55 & -4.51 & 67.23 \\
Utah & 1987 & 6.14 & 7.75 & -11.96 & 66.46 \\
Minnesota & 1987 & 5.99 & 9.00 & -12.03 & 65.85 \\
District of Columbia & 1987 & 5.60 & 10.00 & -11.95 & 66.77 \\
New Mexico & 1987 & 5.38 & 8.50 & -11.67 & 66.96 \\
Idaho & 1987 & 5.20 & 8.20 & -11.54 & 66.59 \\
Delaware & 1987 & 4.92 & 8.80 & -11.47 & 67.87 \\
Kansas & 1987 & 4.83 & 6.71 & -11.19 & 72.86 \\
Montana & 2003 & 4.71 & 9.38 & -3.12 &
\end{tabular}

Notes: This table shows the largest year-by-year changes in top marginal state capital gains tax rates, measured using TAXSIM and presented as percentages. Tax changes are relative to previous year.

Table A.2: Policy Regressions

\begin{tabular}{rllllll}
\hline & \multicolumn{3}{c}{ Tax Increases } & & \multicolumn{2}{c}{ Tax Decreases } \\
& Estimate & Standard Error & & Estimate & Standard Error \\
\cline { 2 - 3 } \cline { 5 - 6 } Unemployment (t-1) & 1.2372 & 0.4009 & & 0.7959 & 0.5581 \\
Unemployment (t-4) & 0.2352 & 0.4537 & & -0.6874 & 0.5517 \\
GDP per capita, USD 1000 (t-1) & -0.0000 & 0.0020 & & 0.0080 & 0.0044 \\
GDP per capita, USD 1000 (t-4) & -0.0014 & 0.0020 & & -0.0077 & 0.0044 \\
Max. state income tax (t-1) & 0.9204 & 0.4928 & & 1.9205 & 0.7455 \\
State corporate tax (t-1) & 0.6303 & 0.2792 & & -0.0142 & 0.3590 \\
State in middle CGT tertile (t-1) & 0.0119 & 0.0268 & & 0.0425 & 0.0378 \\
State in highest CGT tertile (t-1) & 0.0018 & 0.0339 & & 0.0440 & 0.0484 \\
Constant & 0.0036 & 0.0474 & & -0.0132 & 0.0452 \\
\hline
\end{tabular}

Notes: This table shows the results of two OLS regressions aiming to determine whether economic conditions, previous capital gains rates, and other tax rates predict changes in the capital gains tax rate. The outcome variables are dummies for increases and decreases in the state capital gains tax rate at time $t$, respectively. The variables "Unemployment", "Max state income tax" and "State corporate tax" are measured as decimal numbers, not percentages. We do not include fixed effects. Standard errors are clustered at the state level. 
Table A.3: Capital Gains and Income Tax Changes by State-Year

\begin{tabular}{rllll}
\hline \multirow{2}{*}{ Income tax rate } & \multicolumn{5}{c}{ Capital gains tax rate } \\
\cline { 2 - 5 } Decreased & Unchanged & Increased & Total \\
\cline { 2 - 5 } Decreased & $\begin{array}{l}75.1 \% \\
(259)\end{array}$ & $0.7 \%$ & $13.8 \%$ & $14.4 \%$ \\
& & $(10)$ & $(33)$ & $(302)$ \\
Unchanged & $13.6 \%$ & $98.5 \%$ & $18.8 \%$ & $75.4 \%$ \\
& $(47)$ & $(1484)$ & $(45)$ & $(1576)$ \\
& $11.3 \%$ & $0.9 \%$ & $67.4 \%$ & $10.2 \%$ \\
Increased & $(39)$ & $(13)$ & $(161)$ & $(213)$ \\
& $100.0 \%$ & $100.0 \%$ & $100.0 \%$ & $100.0 \%$ \\
Total & $(345)$ & $(1507)$ & $(239)$ & $(2091)$ \\
\hline
\end{tabular}

Notes: This table relates the direction of year-by-year changes in state capital gains and income tax rates. Within each column, the percentages show the share of income tax changes that went in the given direction. The rates used are maximum state capital gains and wage tax rates, calculated for a hypothetical highincome taxpayer for years 1977-2017 by Daniel Feenberg for NBER. Tax changes are relative to previous year. Observation (state-year) counts are in parentheses. 
Table A.4: Capital Gains Semi-Elasticities and Revenue-Maximizing Tax Rates

\begin{tabular}{|c|c|c|c|c|c|}
\hline Specification & $\begin{array}{l}\text { Total elasticity, } \\
\gamma^{C G}\end{array}$ & $\begin{array}{l}\text { Policy elasticity, } \\
\gamma^{R}=\gamma^{C G}-\gamma^{N}\end{array}$ & $\begin{array}{l}\text { Laffer rate, } \\
\qquad \tau^{*}=\frac{-1}{\gamma^{R}}\end{array}$ & $\begin{array}{l}\text { Elasticity with } \\
\text { respect to tax } \\
\varepsilon^{\operatorname{tax}}=\gamma^{R} \cdot \frac{-0.22}{1-0.22}\end{array}$ & $\begin{array}{r}\chi^{2} \text { test: } \\
\varepsilon^{\operatorname{tax}}=-1\end{array}$ \\
\hline \multicolumn{6}{|l|}{ Baseline } \\
\hline $0-10$ years & -5.53 & -2.89 & 0.35 & -0.64 & 1.81 \\
\hline & $(1.35)$ & $(1.23)$ & $(0.15)$ & $(0.27)$ & $(0.18)$ \\
\hline \multirow[t]{2}{*}{$0-2$ years } & -5.23 & -3.21 & 0.31 & -0.71 & 1.12 \\
\hline & $(1.32)$ & $(1.26)$ & $(0.12)$ & $(0.28)$ & $(0.29)$ \\
\hline \multirow[t]{2}{*}{ 3-5 years } & -7.36 & -3.34 & 0.30 & -0.74 & 0.94 \\
\hline & $(1.49)$ & $(1.24)$ & $(0.11)$ & $(0.27)$ & $(0.33)$ \\
\hline \multirow[t]{2}{*}{$6-8$ years } & -6.59 & -3.05 & 0.33 & -0.67 & 1.25 \\
\hline & $(1.70)$ & $(1.33)$ & $(0.14)$ & $(0.29)$ & $(0.26)$ \\
\hline \multirow[t]{2}{*}{$6-10$ years } & -6.04 & -2.39 & 0.42 & -0.53 & 2.38 \\
\hline & $(1.81)$ & $(1.40)$ & $(0.24)$ & $(0.31)$ & $(0.12)$ \\
\hline \multicolumn{6}{|l|}{ Big changes only } \\
\hline \multirow{2}{*}{$0-10$ years } & -4.80 & -2.37 & 0.42 & -0.52 & 3.25 \\
\hline & $(1.34)$ & $(1.20)$ & $(0.21)$ & $(0.26)$ & $(0.07)$ \\
\hline \multirow[t]{2}{*}{0 - 2 years } & -5.55 & -3.74 & 0.27 & -0.82 & 0.35 \\
\hline & $(1.33)$ & $(1.36)$ & $(0.10)$ & $(0.30)$ & $(0.55)$ \\
\hline \multirow[t]{2}{*}{$3-5$ years } & -7.62 & -3.49 & 0.29 & -0.77 & 0.68 \\
\hline & $(1.48)$ & $(1.28)$ & $(0.11)$ & $(0.28)$ & $(0.41)$ \\
\hline \multirow[t]{2}{*}{$6-8$ years } & -6.27 & -2.67 & 0.37 & -0.59 & 1.98 \\
\hline & $(1.68)$ & $(1.33)$ & $(0.19)$ & $(0.29)$ & $(0.16)$ \\
\hline \multirow[t]{2}{*}{$6-10$ years } & -5.01 & -1.78 & 0.56 & -0.39 & 3.66 \\
\hline & $(1.87)$ & $(1.44)$ & $(0.45)$ & $(0.32)$ & $(0.06)$ \\
\hline \multicolumn{6}{|l|}{ Control for other } \\
\hline \multirow[t]{2}{*}{$0-10$ years } & -4.02 & -1.61 & 0.62 & -0.35 & 3.18 \\
\hline & $(1.81)$ & $(1.65)$ & $(0.64)$ & $(0.36)$ & $(0.07)$ \\
\hline \multirow[t]{2}{*}{$0-2$ years } & -3.88 & -1.90 & 0.53 & -0.42 & 2.62 \\
\hline & (1.63) & (1.63) & $(0.45)$ & $(0.36)$ & $(0.11)$ \\
\hline \multirow[t]{2}{*}{$3-5$ years } & -5.68 & -2.35 & 0.42 & -0.52 & 2.24 \\
\hline & $(1.72)$ & $(1.46)$ & $(0.26)$ & $(0.32)$ & (0.13) \\
\hline \multirow[t]{2}{*}{$6-8$ years } & -5.66 & -2.28 & 0.44 & -0.50 & 1.94 \\
\hline & $(2.02)$ & $(1.63)$ & $(0.31)$ & $(0.36)$ & $(0.16)$ \\
\hline \multirow[t]{2}{*}{$6-10$ years } & -5.24 & -2.00 & 0.50 & -0.44 & 2.28 \\
\hline & $(2.20)$ & (1.69) & $(0.42)$ & $(0.37)$ & $(0.13)$ \\
\hline
\end{tabular}

Notes: This table corresponds to Table 2 in the main text, but uses a specification in which the right-hand side variable of interest is the change in the tax rate, rather than in the log net-of-tax rate. Specifically, we use the exact estimation method described in section 2.2 , with the exception that in equation (2), we replace the variable $\Delta_{3} \log \left(1-\tau_{s, t}\right)$ with $\Delta_{3} \tau_{s, t}$, and correspondingly, in (3), $\Delta_{11} \log \left(1-\tau_{s, t}\right)$ is replaced with $\Delta_{11} \tau_{s, t}$. Similarly, the vector of controls for reforms in surrounding years, $\mathbf{X}_{s, t}$, is also specified using the tax rate in levels rather than the log net-of-tax rate. With this change of right-hand-side variables, columns 1 and 2 estimate semi-elasticities in a way completely analogously to how we estimate the corresponding elasticities in Table 2 . In column 3 , we calculate the revenue-maximizing tax rate given the policy-relevant semi-elasticity from column 2 . In a model where the semi-elasticity $\gamma$ is assumed constant, the revenue-maximizing tax rate can be found as $\tau^{*}=-\frac{1}{\gamma}$. In column 4 , we convert our semi-elasticity to an elasticity with respect to the tax rate simply by multiplying by a tax rate of 0.22 . More details on our calculations can be found in Appendix C. Standard errors are clustered at the state level. Values in parentheses in columns 1-4 represent standard errors; values in parentheses in column 5 ( $\chi^{2}$ test) represent p-values. 
Table A.5: Capital Gains Elasticities and Revenue-Maximizing Tax Rates - Event Study Specification

\begin{tabular}{|c|c|c|c|c|c|}
\hline$\underline{\text { Specification }}$ & $\begin{array}{l}\text { Total elasticity, } \\
\varepsilon^{C G}\end{array}$ & $\begin{array}{l}\text { Policy elasticity, } \\
\varepsilon^{R}=\varepsilon^{C G}-\varepsilon^{N}\end{array}$ & $\begin{array}{l}\text { Laffer rate, } \\
\tau^{*}=\frac{1-\bar{\tau}_{S}}{1+\varepsilon^{R}}\end{array}$ & $\begin{array}{l}\text { Elasticity with } \\
\text { respect to tax } \\
\varepsilon^{t a x}=\varepsilon^{R} \cdot \frac{-0.22}{1-0.22}\end{array}$ & $\begin{array}{r}\chi^{2} \text { test: } \\
\varepsilon^{\text {tax }}=-1\end{array}$ \\
\hline \multicolumn{6}{|l|}{ Baseline } \\
\hline $0-10$ years & 3.35 & 1.85 & 0.33 & -0.52 & 5.26 \\
\hline & $(0.90)$ & $(0.74)$ & $(0.08)$ & $(0.21)$ & $(0.02)$ \\
\hline \multirow[t]{2}{*}{0 - 2 years } & 3.13 & 2.14 & 0.30 & -0.60 & 2.65 \\
\hline & $(0.97)$ & $(0.86)$ & $(0.08)$ & $(0.24)$ & $(0.10)$ \\
\hline \multirow[t]{2}{*}{ 3-5 years } & 4.45 & 2.28 & 0.29 & -0.64 & 2.05 \\
\hline & (1.09) & $(0.89)$ & $(0.08)$ & $(0.25)$ & $(0.15)$ \\
\hline \multirow[t]{2}{*}{$6-8$ years } & 3.39 & 1.91 & 0.32 & -0.54 & 3.50 \\
\hline & (1.04) & $(0.87)$ & $(0.10)$ & $(0.25)$ & $(0.06)$ \\
\hline \multirow[t]{2}{*}{$6-10$ years } & 3.00 & 1.41 & 0.39 & -0.40 & 6.34 \\
\hline & $(1.01)$ & $(0.85)$ & $(0.14)$ & $(0.24)$ & $(0.01)$ \\
\hline \multicolumn{6}{|l|}{ Big changes only } \\
\hline \multirow[t]{2}{*}{$0-10$ years } & 2.68 & 1.57 & 0.37 & -0.44 & 7.22 \\
\hline & $(0.94)$ & $(0.74)$ & $(0.10)$ & $(0.21)$ & $(0.01)$ \\
\hline \multirow[t]{2}{*}{0 - 2 years } & 3.48 & 2.72 & 0.25 & -0.77 & 0.72 \\
\hline & $(0.99)$ & $(0.97)$ & $(0.07)$ & $(0.27)$ & $(0.40)$ \\
\hline \multirow[t]{2}{*}{ 3-5 years } & 4.84 & 2.75 & 0.25 & -0.78 & 0.68 \\
\hline & (1.15) & $(0.97)$ & $(0.06)$ & $(0.27)$ & $(0.41)$ \\
\hline \multirow{2}{*}{$6-8$ years } & 3.38 & 2.00 & 0.31 & -0.57 & 2.86 \\
\hline & (1.05) & $(0.91)$ & (0.09) & $(0.26)$ & (0.09) \\
\hline \multirow[t]{2}{*}{$6-10$ years } & 2.44 & 1.30 & 0.41 & -0.37 & 6.38 \\
\hline & $(1.04)$ & $(0.89)$ & $(0.16)$ & $(0.25)$ & $(0.01)$ \\
\hline \multicolumn{6}{|l|}{ Control for other } \\
\hline \multirow[t]{2}{*}{$0-10$ years } & 2.70 & 1.35 & 0.40 & -0.38 & 6.27 \\
\hline & $(0.96)$ & $(0.88)$ & $(0.15)$ & $(0.25)$ & $(0.01)$ \\
\hline \multirow{2}{*}{ 0-2 years } & 2.31 & 1.27 & 0.41 & -0.36 & 4.57 \\
\hline & (1.08) & (1.07) & $(0.19)$ & $(0.30)$ & $(0.03)$ \\
\hline \multirow[t]{2}{*}{ 3-5 years } & 3.47 & 1.69 & 0.35 & -0.48 & 4.03 \\
\hline & $(1.10)$ & $(0.92)$ & $(0.12)$ & $(0.26)$ & $(0.04)$ \\
\hline \multirow[t]{2}{*}{$6-8$ years } & 3.01 & 1.61 & 0.36 & -0.45 & 3.67 \\
\hline & (1.12) & (1.01) & $(0.14)$ & $(0.29)$ & $(0.06)$ \\
\hline \multirow[t]{2}{*}{$6-10$ years } & 2.60 & 1.25 & 0.42 & -0.35 & 5.23 \\
\hline & (1.10) & (1.01) & $(0.19)$ & $(0.28)$ & $(0.02)$ \\
\hline
\end{tabular}

Notes: This table corresponds to Table 2 in the main text, but uses an event study specification where elasticities at different horizons are estimated jointly within the same regression model rather than using separate regressions for each coefficient as in the direct projections case. Specifically, for the three-year bins, instead of equation (2), we run a single regression of the form $y_{s, t}=\beta_{-9} \Delta_{3} \log \left(1-\tau_{s, t+9}\right)+\beta_{-6} \Delta_{3} \log \left(1-\tau_{s, t+6}\right)+\cdots+\beta_{9} \Delta_{3} \log \left(1-\tau_{s, t-9}\right)+\gamma_{s}+\phi_{t}+\varepsilon_{s, t}$. Using capital gains realizations as the outcome variable, we then provide elasticity estimates as the difference between the coefficients $\beta_{t}-\beta-3$ from this regression. Migration elasticities are calculated correspondingly, using our migration variable from the main text as the outcome variable. For the estimates in the 0-10 year and 6-10 year rows, we run separate regressions. For the 0-10 year bin, we run the regression $y_{s, t}=\tilde{\beta}_{-9} \Delta_{3} \log \left(1-\tau_{s, t+9}\right)+\tilde{\beta}_{-6} \Delta_{3} \log \left(1-\tau_{s, t+6}\right)+\tilde{\beta}_{-3} \Delta_{3} \log \left(1-\tau_{s, t+3}\right)+\tilde{\beta}_{0} \Delta_{11} \log \left(1-\tau_{s, t}\right)+\tilde{\gamma}_{s}+\tilde{\phi}_{t}+\tilde{\varepsilon}_{s, t}$ and estimate the 0-10 year elasticity as the difference $\tilde{\beta}_{0}-\tilde{\beta}_{-3}$. Similarly, for the 6-10 year bin, we run the regression $y_{s, t}=$ $\breve{\beta}_{-9} \Delta_{3} \log \left(1-\tau_{s, t+9}\right)+\cdots+\check{\beta}_{0} \Delta_{3} \log \left(1-\tau_{s, t}\right)+\breve{\beta}_{3} \Delta_{3} \log \left(1-\tau_{s, t-3}\right)+\breve{\beta}_{6} \Delta_{5} \log \left(1-\tau_{s, t-6}\right)+\check{\gamma}_{s}+\check{\phi}_{t}+\check{\varepsilon}_{s, t}$ and identify the 6-10 year elasticity as $\breve{\beta}_{6}-\breve{\beta}_{0}$. In the specification that controls for other taxes, we include as variables in the regressions changes in state labor and corporate tax rates over the same year bins as for capital gains taxes. In the "big changes only" specification, like in Table 2, we replace the $\Delta_{q} \log \left(1-\tau_{s, t-r}\right)$-variables with two variables that each sum changes that are smaller and larger than 1 $\mathrm{pp}$, respectively, over the relevant time horizon. See the figure notes to Table 2 for details on this. After estimating the total capital gains and migration elasticities in this way, all other calculations follow exactly as in Table 2. Standard errors are clustered at the state level. Values in parentheses in columns 1-4 represent standard errors; values in parentheses in column 5 ( $\chi^{2}$ test) represent pvalues. 
Table A.6: Capital Gains Elasticities and Revenue-Maximizing Tax Rates with Controls for Unemployment

\begin{tabular}{|c|c|c|c|c|c|}
\hline Specification & $\begin{array}{r}\text { Total elasticity, } \\
\varepsilon^{C G}\end{array}$ & $\begin{array}{l}\text { Policy elasticity, } \\
\varepsilon^{R}=\varepsilon^{C G}-\varepsilon^{N}\end{array}$ & $\begin{array}{l}\text { Laffer rate, } \\
\qquad \tau^{*}=\frac{1-\bar{\tau}_{S}}{1+\varepsilon^{K}}\end{array}$ & $\begin{array}{l}\text { Elasticity with } \\
\text { respect to tax } \\
\varepsilon^{\operatorname{tax}}=\varepsilon^{R} \cdot \frac{-0.22}{1-0.22}\end{array}$ & $\begin{array}{r}\chi^{2} \text { test: } \\
\varepsilon^{t a x}=-1\end{array}$ \\
\hline \multicolumn{6}{|l|}{ Baseline } \\
\hline \multirow[t]{2}{*}{$0-10$ years } & 3.39 & 1.87 & 0.33 & -0.53 & 3.38 \\
\hline & (1.01) & $(0.91)$ & $(0.10)$ & $(0.26)$ & $(0.07)$ \\
\hline \multirow{2}{*}{0 - 2 years } & 3.32 & 2.09 & 0.30 & -0.59 & 2.58 \\
\hline & $(0.97)$ & $(0.91)$ & (0.09) & $(0.26)$ & $(0.11)$ \\
\hline \multirow[t]{2}{*}{ 3-5 years } & 4.78 & 2.28 & 0.29 & -0.64 & 2.05 \\
\hline & (1.10) & $(0.88)$ & $(0.08)$ & $(0.25)$ & $(0.15)$ \\
\hline \multirow[t]{2}{*}{$6-8$ years } & 4.07 & 1.94 & 0.32 & -0.55 & 3.02 \\
\hline & $(1.20)$ & $(0.92)$ & $(0.10)$ & $(0.26)$ & $(0.08)$ \\
\hline \multirow[t]{2}{*}{$6-10$ years } & 3.66 & 1.47 & 0.38 & -0.41 & 4.54 \\
\hline & $(1.27)$ & $(0.97)$ & $(0.15)$ & $(0.27)$ & $(0.03)$ \\
\hline \multicolumn{6}{|l|}{$\begin{array}{l}\text { Control for } \\
\text { unemployment }\end{array}$} \\
\hline \multirow[t]{2}{*}{$0-10$ years } & 3.24 & 1.79 & 0.34 & -0.51 & 3.87 \\
\hline & $(0.98)$ & $(0.89)$ & $(0.11)$ & $(0.25)$ & $(0.05)$ \\
\hline \multirow[t]{2}{*}{0 - 2 years } & 3.36 & 2.03 & 0.31 & -0.57 & 2.74 \\
\hline & $(0.98)$ & $(0.92)$ & $(0.09)$ & $(0.26)$ & $(0.10)$ \\
\hline \multirow[t]{2}{*}{ 3-5 years } & 4.71 & 2.15 & 0.30 & -0.61 & 2.80 \\
\hline & (1.14) & $(0.84)$ & $(0.08)$ & $(0.24)$ & $(0.09)$ \\
\hline \multirow[t]{2}{*}{$6-8$ years } & 3.87 & 1.76 & 0.34 & -0.50 & 4.24 \\
\hline & $(1.26)$ & $(0.87)$ & $(0.11)$ & $(0.24)$ & $(0.04)$ \\
\hline \multirow[t]{2}{*}{$6-10$ years } & 3.45 & 1.39 & 0.39 & -0.39 & 5.10 \\
\hline & $(1.22)$ & $(0.96)$ & $(0.16)$ & $(0.27)$ & $(0.02)$ \\
\hline \multicolumn{6}{|l|}{$\begin{array}{l}\text { Control for } \\
\text { unemployment } \\
\text { growth }\end{array}$} \\
\hline \multirow[t]{2}{*}{$0-10$ years } & 3.04 & 1.94 & 0.32 & -0.55 & 3.20 \\
\hline & $(0.94)$ & $(0.90)$ & $(0.10)$ & $(0.25)$ & $(0.07)$ \\
\hline \multirow[t]{2}{*}{0 - 2 years } & 3.02 & 2.17 & 0.30 & -0.61 & 2.14 \\
\hline & $(0.94)$ & $(0.94)$ & $(0.09)$ & $(0.27)$ & $(0.14)$ \\
\hline \multirow[t]{2}{*}{ 3-5 years } & 4.56 & 2.37 & 0.28 & -0.67 & 1.91 \\
\hline & $(1.07)$ & $(0.85)$ & $(0.07)$ & $(0.24)$ & $(0.17)$ \\
\hline \multirow[t]{2}{*}{$6-8$ years } & 3.92 & 1.93 & 0.32 & -0.54 & 2.89 \\
\hline & $(1.24)$ & $(0.95)$ & $(0.10)$ & $(0.27)$ & $(0.09)$ \\
\hline \multirow[t]{2}{*}{6 -10 years } & 3.59 & 1.63 & 0.36 & -0.46 & 3.99 \\
\hline & (1.18) & $(0.96)$ & $(0.13)$ & $(0.27)$ & $(0.05)$ \\
\hline
\end{tabular}

Notes: This table provides additional alternative specifications to our main estimation, beyond those shown in Table 2 in the main text. The top panel of this table, labelled "Baseline", corresponds exactly to the Baseline panel in Table 2. The next two panels add controls for unemployment in two different ways. The middle panel includes a linear control for the state's unemployment rate prior to the capital gains tax reform in question. The bottom panel instead controls for a set of dummies interacting unemployment growth tertiles and years, where the unemployment growth tertile is determined separately in each year by grouping states according to unemployment growth over three years prior to the reform. Standard errors are clustered at the state level. Values in parentheses in columns 1-4 represent standard errors; values in parentheses in column 5 ( $\chi^{2}$ test) represent p-values. 
Table A.7: Capital Gains Elasticities and Revenue-Maximizing Tax Rates with Controls for Other Taxes and Unemployment

\begin{tabular}{|c|c|c|c|c|c|}
\hline Specification & $\begin{array}{r}\text { Total elasticity, } \\
\varepsilon^{C G}\end{array}$ & $\begin{array}{l}\text { Policy elasticity, } \\
\varepsilon^{R}=\varepsilon^{C G}-\varepsilon^{N}\end{array}$ & $\begin{array}{l}\text { Laffer rate, } \\
\tau^{*}=\frac{1-\bar{\tau}_{S}}{1+\varepsilon^{R}}\end{array}$ & $\begin{array}{l}\text { Elasticity with } \\
\text { respect to tax } \\
\varepsilon^{t a x}=\varepsilon^{R} \cdot \frac{-0.22}{1-0.22}\end{array}$ & $\begin{array}{r}\chi^{2} \text { test: } \\
\varepsilon^{\text {tax }}=-1\end{array}$ \\
\hline \multicolumn{6}{|l|}{ Control for other } \\
\hline \multirow[t]{2}{*}{$0-10$ years } & 2.28 & 1.01 & 0.47 & -0.29 & 4.64 \\
\hline & $(1.32)$ & $(1.18)$ & $(0.27)$ & $(0.33)$ & $(0.03)$ \\
\hline \multirow[t]{2}{*}{$0-2$ years } & 2.38 & 1.25 & 0.42 & -0.35 & 3.88 \\
\hline & (1.19) & (1.16) & $(0.21)$ & $(0.33)$ & $(0.05)$ \\
\hline \multirow[t]{2}{*}{ 3-5 years } & 3.58 & 1.64 & 0.36 & -0.46 & 3.54 \\
\hline & $(1.24)$ & (1.01) & $(0.14)$ & $(0.29)$ & $(0.06)$ \\
\hline \multirow[t]{2}{*}{$6-8$ years } & 3.32 & 1.40 & 0.39 & -0.39 & 3.57 \\
\hline & $(1.43)$ & $(1.14)$ & $(0.19)$ & $(0.32)$ & $(0.06)$ \\
\hline \multirow[t]{2}{*}{$6-10$ years } & 2.98 & 1.18 & 0.43 & -0.33 & 3.96 \\
\hline & $(1.54)$ & $(1.19)$ & $(0.24)$ & $(0.34)$ & $(0.05)$ \\
\hline \multicolumn{6}{|l|}{$\begin{array}{l}\text { Control for taxes, } \\
\text { unemployment }\end{array}$} \\
\hline \multirow[t]{2}{*}{$0-10$ years } & 2.22 & 0.96 & 0.48 & -0.27 & 4.83 \\
\hline & (1.30) & $(1.18)$ & $(0.29)$ & $(0.33)$ & $(0.03)$ \\
\hline \multirow[t]{2}{*}{0 -2 years } & 2.35 & 1.20 & 0.43 & -0.34 & 3.92 \\
\hline & $(1.23)$ & (1.18) & $(0.23)$ & $(0.33)$ & $(0.05)$ \\
\hline \multirow[t]{2}{*}{ 3-5 years } & 3.51 & 1.57 & 0.36 & -0.44 & 3.84 \\
\hline & (1.33) & $(1.01)$ & $(0.14)$ & $(0.28)$ & $(0.05)$ \\
\hline \multirow[t]{2}{*}{$6-8$ years } & 3.18 & 1.31 & 0.41 & -0.37 & 4.11 \\
\hline & $(1.47)$ & $(1.10)$ & $(0.19)$ & $(0.31)$ & $(0.04)$ \\
\hline \multirow[t]{2}{*}{$6-10$ years } & 2.94 & 1.13 & 0.44 & -0.32 & 4.23 \\
\hline & $(1.48)$ & $(1.18)$ & $(0.24)$ & $(0.33)$ & $(0.04)$ \\
\hline \multicolumn{6}{|l|}{$\begin{array}{l}\text { Control for taxes, } \\
\text { unemployment } \\
\text { growth }\end{array}$} \\
\hline \multirow[t]{2}{*}{$0-10$ years } & 2.21 & 1.06 & 0.45 & -0.30 & 4.67 \\
\hline & $(1.20)$ & $(1.15)$ & $(0.25)$ & $(0.32)$ & $(0.03)$ \\
\hline \multirow[t]{2}{*}{$0-2$ years } & 2.31 & 1.31 & 0.41 & -0.37 & 3.68 \\
\hline & $(1.12)$ & $(1.16)$ & $(0.20)$ & $(0.33)$ & $(0.05)$ \\
\hline \multirow[t]{2}{*}{ 3-5 years } & 3.55 & 1.70 & 0.35 & -0.48 & 3.68 \\
\hline & $(1.20)$ & $(0.96)$ & $(0.12)$ & $(0.27)$ & $(0.05)$ \\
\hline \multirow[t]{2}{*}{$6-8$ years } & 3.38 & 1.38 & 0.39 & -0.39 & 4.01 \\
\hline & $(1.41)$ & (1.08) & $(0.18)$ & $(0.30)$ & $(0.05)$ \\
\hline \multirow{2}{*}{$6-10$ years } & 3.08 & 1.25 & 0.42 & -0.35 & 4.23 \\
\hline & $(1.45)$ & $(1.12)$ & $(0.21)$ & $(0.31)$ & $(0.04)$ \\
\hline
\end{tabular}

Notes: This table provides additional alternative specifications to our main estimation, beyond those shown in Table 2 in the main text. The top panel of this table, labelled "Control for other taxes", controls for changes in state labor and corporate taxes, and corresponds exactly to the bottom panel in Table 2 - see the notes to Table 2 for further details on how this is specified. The next two panels in this table include the same controls for other state tax changes, but also control for unemployment in two different ways. The middle panel includes a linear control for the state's unemployment rate prior to the capital gains tax reform in question. The bottom panel instead controls for a set of dummies interacting unemployment growth tertiles and years, where the unemployment growth tertile is determined separately in each year by grouping states according to unemployment growth over three years prior to the reform. Standard errors are clustered at the state level. Values in parentheses in columns 1-4 represent standard errors; values in parentheses in column 5 ( $\chi^{2}$ test) represent p-values. 


\section{B Data Appendix}

This appendix covers our data sources in more detail and clarifies adjustments and assumptions that have been made in cleaning and processing the data.

\section{Tax rates}

- Maximum federal, state, and total tax rates on long-term capital gains for the years 1977 to 2017 are obtained from NBER TAXSIM data. These data are calculated by simulating the effect of a change in income for a hypothetical high earner in the TAXSIM model, and thus incorporate statutory state tax rates as well as phaseouts of exemptions and itemized deductions. In some specifications, we control for changes in the maximum state income tax and corporate tax rates, which we also obtain from this dataset. ${ }^{14}$

- Table 1 shows maximum federal long-term capital gains tax rates, which we obtain from the US Department of the Treasury. ${ }^{15}$ As of the time of writing, the Treasury data starts in 1954, but unfortunately only goes to 2014. Knowing that the maximum statutory tax rate on capital gains did not change between 2014 and 2017, we manually extend the data forwards, assuming a tax range that is unchanged from its 2014 level. Since the data also includes the effects of other minor provisions on maximum tax rates, it is possible that we are leaving out smaller changes in the maximum tax rate through our extrapolation. However, we expect any such discrepancies to be small, as the maximum effective tax rate is very close to the maximum statutory rate for recent years. In the data, certain years contain two different tax rates. In these cases, the capital gains tax rate changed at some point during the year, and different tax rates applied for gains that were realized in different parts of the years. Since our data on realized capital gains are at the year level, we are unable to apply these different tax rates over the year. Therefore, for these few years, we assume the relevant tax rate to be the midpoint between the two tax rates that applied over the year.

- Data on UK tax rates comes from HM Revenue and Customs. ${ }^{16}$ Note that for some of the years in question, the UK had different tax rates for individuals and trusts. For the purposes of our analysis, we ignore trusts, which account for a comparatively small and stable amount of capital gains across the years we study.

\section{Realized capital gains}

- Data on realized capital gains at the federal level are obtained from the appendix tables of Piketty, Saez and Zucman (2018). ${ }^{17}$ Specifically, the numbers we use can be found in column 21 of Table C1. These numbers were calculated by Piketty, Saez and Zucman (2018) as aggregates of the NBER micro-files samples of tax returns and correspond to the fikgi variable. ${ }^{18}$ Note that these are net long-term plus short-term capital gains, i.e., any capital losses are subtracted from the total in each year. ${ }^{19}$

- Data on realized capital gains at the state level are taken from Smith, Zidar and Zwick (2020). The series that we use comes from a state-year collapse of the fikgi variable in the IRS SOI sample files. We also use data from the same source on the number of residents by state within the top 1 and $10 \%$ of the national wealth distribution.

\footnotetext{
${ }^{14}$ Further background information and the dataset itself are available at https://users.nber.org/ taxsim/state-rates/.

${ }^{15}$ These data are currently available in excel format at https://www.treasury.gov/resource-center/tax-policy/ tax-analysis/Documents/Taxes-Paid-on-Capital-Gains-for-Returns-with-Positive-Net-Capital-Gains.xlsx.

${ }^{16}$ Specifically, it can be found at https://assets.publishing.service.gov.uk/government/uploads/system/uploads/ attachment_data/file/764247/Table_A1.pdf. Note that we do not currently use these data directly in our analysis, except to verify that the UK did not change its capital gains tax rate at any time during the periods in which we use it as a control group to the US. Capital gains were treated as part of regular income throughout all of the years in our UK sample. The maximum income tax rate throughout this period was 40 percent.

${ }^{17}$ Currently, these can be found under http://gabriel-zucman.eu/files/PSZ2017AppendixTablesI(Macro).xlsx

${ }^{18}$ See the Piketty, Saez and Zucman (2018) codebook here http://gabriel-zucman.eu/files/PSZCodebook.pdf.

${ }^{19}$ In future work, it would be valuable to consider gains and losses separately and test where the inclusion of net short term gains and losses and netting of loss carryovers from past years have different effects.
} 
- UK data on realized net capital gains comes from HM Revenue and Customs. ${ }^{20}$ These data are given separately for individuals and trusts, which are taxed at different rates over the period that we study. We only use the data for individuals, who are taxed at a 40 percent rate throughout all the years that we study. For specific types of trusts, the tax rate did change slightly over the period that we study. Our choice to only use realized capital gains by individuals is therefore based on an assumption that any spillover effects between the two tax bases resulting from changes in the trust tax rate are negligible. We view this as a reasonable assumption since capital gains by trusts is a small and relatively stable share of total capital gains, since only certain types of trusts (i.e, interest in possession trusts and personal representative) were subject to tax changes over the period we study, and since the tax changes were very small, changing by only 3 percentage points over the period.

\section{Other variables}

- In some specifications, we control for state GDP numbers obtained from the Bureau of Economic Analysis. $^{21}$

- Other specifications control for unemployment, which we obtain from the Bureau of Labor Statistics. ${ }^{22}$

- To generate variables in per capita terms, we use annual estimates of US state populations from the US Census Bureau, obtained through the St. Louis Fed. ${ }^{23}$

- We convert dollar amounts into real values using the CPI for urban consumers (CPI-U), obtained from the US Bureau of Labor Statistics. ${ }^{24}$

- Nominal values from the UK are deflated using the Retail Price Index, avalable from the Office for National Statistics. ${ }^{25}$

\footnotetext{
${ }^{20}$ They can be found at https://www.gov.uk/government/statistics/capital-gains-tax-statistical-tables

${ }^{21}$ These can be found using the Regional Economic Accounts download tool at https://apps.bea.gov/regional/ downloadzip.cfm.

${ }^{22}$ Available at https ://www.bls.gov/lau/\#data.

${ }^{23}$ These can be obtained as a single zip file by using the download tool at https://research.stlouisfed.org/pdl/628/ download.

${ }^{24}$ Available at https://www.bls.gov/cpi/data.htm.

25 https ://www.ons.gov.uk/economy/inflationandpriceindices/datasets/consumerpriceindices.
} 


\section{On Elasticities and Semi-Elasticities}

Our approach in equation (1) relates log capital gains realizations to the log net-of-tax rate, which is a standard approach in much of the recent literature on the elasticity of taxable income (e.g., Gruber and Saez, 2002; Saez, Slemrod and Giertz, 2012; Kleven and Schultz, 2014; Doerrenberg, Peichl and Siegloch, 2017), where the log net-of-tax rate (or changes in the log net-of-tax rate) is often used as the primary explanatory variable. One reason for this formulation is that the net-of-tax price is often the relevant price governing behavior in standard economic models. ${ }^{26}$ However, most of the previous literature on capital gains taxes (e.g., Bogart and Gentry, 1995; Bakija and Gentry, 2014; Dowd, McClelland and Muthitacharoen, 2015) has related log capital gains to the linear tax rate or net-of-tax rate, fitting specifications of the semi-log form:

$$
\log C G_{t}=\gamma \cdot \tau_{t} .
$$

In a model of this form, the coefficient $\gamma$ corresponds to a semi-elasticity of capital gains realizations with respect to the tax rate. Empirically, given the variation we observe in tax rates, it is hard to determine whether our baseline model in equation (1) fits the data better than a model of this type. ${ }^{27}$ However, the two models generate different predictions about how behavioral responses scale with tax rates. Whereas our baseline model would imply that a 1 percentage point change in the tax rate induces larger realizations responses when the tax rate is higher, the model in (C.1) implies that a 1 percentage point change in tax rates would always generate the same percentage change in realizations. As we illustrate in Appendix Figure A.6, the difference between the predictions of these models grows larger when the tax rate is extrapolated further from the rate at which both semi-elasticity and net-of-tax rate elasticity are calculated. This difference can be important, for instance, when using these models to calculate the implied revenue-maximizing tax rate.

We use the model in equation (1) as our baseline model because it is standard in the broader taxable elasticity literature and may generate more realistic predictions when considering implied behavioral responses at large tax rates. For example, the model in (C.1) implies that the percentage change in realizations would be the same whether tax rates were increased from 20 to 21 percent or from 99 to 100 percent, which seems less accurate given standard predictions about distortions growing with the square of the tax rate. Our model, in contrast, would predict much larger responses when tax rates are high.

\section{C.1 Empirical Estimates Using a Semi-Log Specification}

We provide results estimation using semi-log specifications to facilitate comparisons to the prior literature and to assess the robustness of our estimates. We report these semi-log results in Table A.4, which has the same structure as Table 2 with our binned multi-year estimates from the main text, but with various changes as outlined below.

In the first column of Table A.4, we estimate the empirical semi-elasticity, which we label $\gamma^{C G}$. We do so using the same procedure described in Section 2.2 in the main text, but with the right hand-side variable of interest changed. For instance, instead of equation (2), we estimate:

$$
y_{s, t+h}=\tilde{\theta}_{h} \Delta_{3} \tau_{s, t}+\mathbf{X}_{s, t}^{\prime} \tilde{\Lambda}_{h}+\tilde{\mu}_{s, h}+\tilde{\phi}_{t, h}+\tilde{\varepsilon}_{s, t, h}
$$

Just as we do for the elasticities in the main text, we calculate the semi-elasticity based on these estimates as the difference between post- and pre-reform point estimates. For example, the 0-2 year semi-elasticity is calculated as $\tilde{\gamma}_{0} \equiv \tilde{\theta}_{0}-\tilde{\theta}_{-3}$, the 3-5 year semi-elasticity as $\tilde{\gamma}_{3} \equiv \tilde{\theta}_{3}-\tilde{\theta}_{-3}$, and so on. Also note that in this specification, the vector of controls for reforms in surrounding years, $\mathbf{X}_{s, t}$, is also specified in terms of the tax rate in levels, i.e., it contains the variables $\Delta_{3} \tau_{s, t+r}$ for $r=-9,-6,-3,3,6,9$.

In the second column of Table A.4, we obtain a semi-elasticity that differences out the migration effect by subtracting the point estimates of $\gamma^{N}$ from a specification like (C.2) with $\theta_{s} \ln N_{s, t}^{P 99-P 100}+\left(1-\theta_{s}\right) \ln N_{s, t}^{P 90-P 100}$ as the outcome variable. This step is completely analogous to what we do in Table 2 for our main estimates. ${ }^{28}$

\footnotetext{
${ }^{26}$ For example, labor supply decisions depend on the net-of-tax wage, i.e., $(1-\tau) w$, in standard models of labor supply.

${ }^{27}$ Figure A.5 shows that there is little difference in how strongly changes in log realized capital gains correlate with changes in net-of-tax rates and log net-of-tax rates, respectively.

${ }^{28}$ One small difference is that unlike in Table 2, we do not multiply by the minor adjustment factor that we describe in Appendix E. This adjustment is not needed in a model where semi-elasticities are assumed constant for all tax rates. We can see this point by repeating the simplification from equation (E.4) in the context of a semi-elasticity model. Specifically, let $\gamma \equiv$ $\frac{\mathrm{d} C G}{\mathrm{~d} \tau} \cdot \frac{1}{C G}$ be the policy-relevant semi-elasticity at a national level (corresponding to $\varepsilon$ in (E.4)), and let $\gamma^{R} \equiv \frac{\mathrm{d} \log R_{s}}{\mathrm{~d} \tau}=\frac{\mathrm{d} R_{s}}{\mathrm{~d} \tau} \cdot \frac{1}{R_{s}}$
} 
We then go on to calculate the revenue-maximizing tax rate implied by the estimated policy-relevant semielasticities. As in Appendix E, this is the tax rate that solves the federal government's revenue maximization problem,

$$
\begin{aligned}
\tau_{F}^{*} & =\arg \max _{\tau_{F}} \tau_{F} \cdot C G \\
& =\arg \max _{\tau_{F}} \log \tau_{F}+\log C G
\end{aligned}
$$

Taking the first order condition for maximization with respect to $\tau_{F}$ in the second line, we get:

$$
0=\frac{1}{\tau_{F}}+\frac{\mathrm{d} \log C G}{\mathrm{~d} \tau_{F}}
$$

which rearranges to

$$
\tau_{F}^{*}=-\frac{1}{\gamma},
$$

where $\gamma \equiv \frac{\mathrm{d} C G}{\mathrm{~d} \tau_{F}} \cdot \frac{1}{C G}=\frac{\mathrm{d} \log C G}{\mathrm{~d} \tau_{F}}$ is the policy-relevant semi-elasticity at a national level. Note that unlike in our main analysis, where we find the formula for the revenue-maximizing tax rate in equation (6), we do not adjust for the average state taxes here. That is because in a model with a constant semi-elasticity, state taxes are irrelevant for the federal tax; differences in the baseline tax rate do not affect the magnitude of behavioral responses. In other words, in this model, if the semi-elasticity is -4 , the revenue-maximizing federal tax rate is $25 \%$, regardless of whether average state taxes are 0 or $50 \%$.

Finally, in the fourth column of Table A.4, we convert the estimated policy-relevant semi-elasticity to an elasticity with respect to the tax rate, evaluated at $22 \%$ to facilitate comparison to Table 2 and the prior literature as referenced in Gravelle (2020). Since the semi-elasticity is given by $\gamma=\frac{\mathrm{d} C G}{\mathrm{~d} \tau} \cdot \frac{1}{C G}$, it can be converted into a tax elasticity at any given tax rate $\tau$ by simply multiplying it by $\tau$.

Our results in Table A.4 are broadly consistent with what we find in Table 2. While the first two columns are not directly comparable, we find that the semi-log specification delivers tax elasticities that are slightly larger than those in our main specification. However, despite differences in how revenue-maximizing tax rates are calculated in the two models, we get similar estimates of the revenue-maximizing tax rate across our various specifications.

be the realizations semi-elasticity at the state level. We then find:

$$
\begin{aligned}
\gamma & =\frac{\mathrm{d} C G}{\mathrm{~d} \tau} \cdot \frac{1}{C G} \\
& =\left[\sum_{s \in S} N_{s} \frac{\mathrm{d} R_{s}}{\mathrm{~d} \tau}\right] \cdot \frac{1}{\sum_{s \in S} N_{s} R_{s}} \\
& =\left[\sum_{s \in S} N_{s} \gamma^{R} \cdot R_{s}\right] \cdot \frac{1}{\sum_{s \in S} N_{s} R_{s}} \\
& =\gamma^{R}\left[\sum_{s \in S} N_{s} R_{s}\right] \cdot \frac{1}{\sum_{s \in S} N_{s} R_{s}} \\
& =\gamma^{R} .
\end{aligned}
$$




\section{Estimation Using Simulated Data}

This section presents the results of two simulation exercises that aim to examine whether our estimation methods are biased when estimating the empirical elasticity of capital gains with respect to the net-of-tax rate. We use our actual empirical data on the maximum combined state and federal capital gains tax rate, but rather than use empirical data on realized capital gains as the outcome variable, we simulate this variable in such a way that we know the true empirical elasticity for this simulated variable with respect to the net-of-tax rate. We start with a simulation that features an elasticity that is constant across all time horizons, before moving on to the more complex case of a time-varying elasticity.

\section{D.1 Simulation with constant elasticity}

First, we generate the simulated log capital gains variable according to the following formula:

$$
\log C G_{s, t}^{s i m}=10+1 \cdot \text { fips }_{s}+2 \cdot t+2 \cdot \log \left(1-\tau_{s, t}\right)+\eta_{s, t} .
$$

From this data-generating process, it is clear to see that the "true" empirical elasticity of capital gains with respect to the net-of-tax rate will be $\varepsilon^{C G}=\frac{\partial \log C G_{s, t}^{s i m}}{\partial \log \left(1-\tau_{s, t}\right)}=2$. The constant 10 and the terms $1 \cdot$ fips $_{s}+2 \cdot t$ are chosen arbitrarily - they are simply there to generate a time trend and some variation across states which will be absorbed by state and year fixed effects in our estimation anyway - mimicking structural time trends and differences across states which are unrelated to the tax rate. ${ }^{29}$ The term $\eta_{s, t}$ is a random variable with mean 0 and standard deviation 0.001. In reality, the short-term and long-term elasticities likely differ, which we explore in more detail in subsection D.2. Here, we have here simplified matters and assumed a single permanent elasticity of 2, which holds for both the short and the long term. This is for expositional purposes, since it will make any bias in the different estimation methods easier to see visually.

Having generated this simulated capital gains realizations variable, we now estimate empirically the effect of capital gains tax reforms on it, using various methods. The results of these estimations are shown in Appendix Figure A.14. First, in panel (a), we use our main specification - the baseline direct projections specification from equation (1), which includes a set of controls for other capital gains reforms in the 10 years before and after each reform that enters our regressions. This figure is thus analogous to Figure 2 (a) in the main text, but with simulated outcome data. If our estimation method is accurate, the figure should display a completely flat trend in the pre-and post-periods, with a single upward jump of size 2 from year -1 to 0 . The results show we accurately identify the true elasticity of 2 in the simulated data. There is a clear jump from time -1 to time 0 , the pre-trend is flat, and the trend in the post-period is almost entirely flat as well, with just a very slight upward trend. ${ }^{30}$

Panel (b) of Figure A.14 uses the same estimation method, but omits our controls for capital gains reforms at different horizons. We see that not controlling for other capital gains tax changes performs worse. While the jump at time 0 is still exactly 2, we now have a clear downward trend both before and after the reform year. This pattern reflects the fact that tax reforms in our data tend to be somewhat mean-reverting, as we show in Appendix Figure A.4 and discuss briefly in section 2.. Because of this mean-reversion, the difference between tax rates at time 0 and -1 will tend to be an overestimate of the difference between rates at time $h$ and -1 for $h>0$, and because we are overestimating the size of the tax change, we will correspondingly underestimate the magnitude of the elasticity at these longer horizons.

Finally, panel (c) of Figure A.14 uses an event study method. We use the following specification:

$$
\log C G_{s, t}^{s i m}=\sum_{h=-10}^{10} \beta_{h} \Delta \log \left(1-\tau_{s, t-h}\right)+\gamma_{s}+\delta_{t}+\varepsilon_{s, t},
$$

and the figure plots the point estimates that are normalized relative to period -1 , i.e. it shows $\beta_{-10}-\beta_{-1}, \beta_{-9}-$ $\beta_{-1}, \ldots, \beta_{10}-\beta_{-1}$. This differs from our baseline direct projections specification from equation (1) in that all the point estimates are generated within the same regression. We see that this method performs better than

\footnotetext{
${ }^{29}$ fips $_{s}$ is literally just the FIPS code corresponding to state $s$, which is included as a crude way to ensure that the mean of $\log C G^{\text {sim }}$ will vary across states.

${ }^{30} \mathrm{An}$ alternative specification that is similar to equation (1), but using $y_{s, t+h}-y_{s, t-1}$ as the outcome variable, would in fact remove this very slight bias. However, we have opted not to use this specification for our empirical analysis, as it would not extend naturally to our long multi-year binned specifications, and therefore we do not present it here either.
} 
the direct projections method without controls, but worse than the direct projections with controls, since there is still somewhat of a downward trend. This result is likely because given the specification that we use, we are unable to bin tax reforms that occur beyond the endpoints of our window of 10 leads and lags around the realization year. ${ }^{31}$

Overall, these results show that our main direct projections method with controls is accurately identifying the true elasticity in the longer run. In the next subsection, we extend the simulation exercise to show that our estimation methods also accurately identify true elasticities when they differ across time horizons.

\section{D.2 Simulation with time-varying elasticity}

To simulate a $\log$ realized capital gains variable with a varying net-of-tax elasticity over time, we slightly alter the simulated variable we introduced in equation (D.1). It now becomes:

$$
\begin{aligned}
\log C G_{s, t}^{s i m}= & 10+1 \cdot \text { fips }_{s}+2 \cdot t+2 \cdot \log \left(1-\tau_{s, t}\right) \\
& +1 \cdot\left[\Delta \log \left(1-\tau_{s, t}\right)+\Delta \log \left(1-\tau_{s, t-1}\right)+\Delta \log \left(1-\tau_{s, t-2}\right)\right] \\
& -1 \cdot\left[\Delta \log \left(1-\tau_{s, t-3}\right)+\Delta \log \left(1-\tau_{s, t-4}\right)+\Delta \log \left(1-\tau_{s, t-5}\right)\right] \\
& +\eta_{s, t}
\end{aligned}
$$

In this specification, the long-run elasticity of capital gains with respect to the net-of-tax rate is still 2 , but the added terms modify this elasticity in the short and medium run. The first bracketed term increases the impact of the change in the net-of-tax rate on realizations by 1 for reforms that happened 0,1 or 2 years ago, which means that the elasticity in these three years will now be 3 . Similarly, the second bracketed term decreases the impact of a reform that happened 3,4 or 5 years ago on capital gains realizations, lowering the elasticity in each of these three years to 1 .

We now estimate our baseline specification from equation (1) with this new outcome variable. The result is shown in panel (a) of Figure A.15. We clearly see that our estimation method accurately picks up on the time-varying elasticity across different years, which confirms that this specification also does a good job of capturing the dynamics of the empirical capital gains elasticity around a tax reform.

Panel (b) of Figure A.15 estimates the impact of capital gains reforms on the same simulated outcome variable using the binned specifications in equations (2) and (3). We see that the 3 -year binned specification also captures the dynamics of the elasticity, and the long 0-10-year specification captures the average elasticity across time (the three short-run years with an elasticity of 3 and the three medium-run years with an elasticity of 1 average out to an elasticity of 2 across these six years). Overall, these results confirm that our empirical methods are well-suited to capture the magnitude and evolution of empirical capital gains elasticities over time.

\footnotetext{
${ }^{31}$ Specifiying the right-hand side variables in the event study specification in levels rather than first differences could help deal with this problem, but would also make our empirical estimates harder to compare directly with those from the direct projections specification.
} 


\section{E Full Model}

This section contains further details and derivations for the model outlined in section 4.1 of the main text. We first show the derivations of the formula for the revenue-maximizing tax rate provided in the text. Consider the revenue maximization problem of the national government. ${ }^{32}$ Let $\bar{\tau}_{S}$ denote the average state tax rate. ${ }^{33}$ The government sets $\tau_{F}$ to maximize revenue:

$$
\max _{\tau_{F}} \tau_{F} \cdot C G
$$

where $C G=\sum_{s \in S} C G_{s}=\sum_{s \in S} N_{s}\left(1-\tau_{F}-\tau_{s}, \tau_{-s}\right) R_{s}\left(1-\tau_{F}-\tau_{s}\right)$. Taking logs in (E.1), we get the first order condition

$$
\frac{1}{\tau_{F}}=-\frac{\mathrm{d} \log C G}{\mathrm{~d} \tau_{F}}
$$

which is equivalent to

$$
\begin{aligned}
\frac{1}{\tau_{F}} & =\frac{\mathrm{d} \log C G}{\mathrm{~d}\left(1-\tau_{F}-\bar{\tau}_{S}\right)} \\
& =\frac{\mathrm{d} \log C G}{\mathrm{~d} \log \left(1-\tau_{F}-\bar{\tau}_{S}\right)} \cdot \frac{\mathrm{d} \log \left(1-\tau_{F}-\bar{\tau}_{S}\right)}{\mathrm{d}\left(1-\tau_{F}-\bar{\tau}_{S}\right)} \\
& =\frac{\mathrm{d} \log C G}{\mathrm{~d} \log \left(1-\tau_{F}-\bar{\tau}_{S}\right)} \cdot \frac{1}{1-\tau_{F}-\bar{\tau}_{S}}
\end{aligned}
$$

We can rewrite this expression to find that the revenue-maximizing tax rate is

$$
\tau_{F}^{*}=\frac{1-\bar{\tau}_{S}}{1+\varepsilon}
$$

where

$$
\varepsilon=\frac{\mathrm{d} \log C G}{\mathrm{~d} \log \left(1-\tau_{F}-\bar{\tau}_{S}\right)}=\frac{\mathrm{d} C G}{\mathrm{~d}\left(1-\tau_{F}-\bar{\tau}_{S}\right)} \cdot \frac{\left(1-\tau_{F}-\bar{\tau}_{S}\right)}{C G} .
$$

We call this elasticity the policy-relevant elasticity since it is a sufficient statistic for determining revenuemaximizing rates at the federal level. We would like to express this elasticity in terms of the realization elasticities $\varepsilon^{R}$ that we described in equation (5), since they are what we can empirically estimate. To simplify the expression in (E.3), we impose two fairly reasonable assumptions.

Assumption 1: In every region, $n_{s}$ is unaffected by the federal tax rate. Mathematically, this means that

$$
\frac{\mathrm{d} n_{s}\left(1-\tau_{F}-\tau_{1}, 1-\tau_{F}-\tau_{2}, \ldots, 1-\tau_{F}-\tau_{s}, \ldots\right)}{\mathrm{d} \tau_{F}}=0 \quad \text { for all } s \in S .
$$

In reality, it might be hard to find a function for which this is indeed exactly true everywhere on its domain. However, within the range of usual tax rates that we consider, it seems like a reasonable first degree approximation that a change in national tax rates wouldn't directly cause internal migration between regions.

Assumption 2: Realization elasticities are homogenous across regions, $\varepsilon_{s}^{R}=\varepsilon^{R}$ for all $s \in S$.

\footnotetext{
${ }^{32}$ Changes in the capital gains rate may affect other types of income (e.g., dividends, wage and salary income, etc.). This formula does not account for spillovers to other parts of the tax base, so we may actually be underestimating the revenue maximizing capital gains rate. Estimating these fiscal spillovers precisely is difficult empirically. Another relevant issue is the negative vertical fiscal externality between federal and state governments-maximizing federal revenues is different from maximizing federal plus state revenues.

${ }^{33}$ This average is weighted by state populations $N_{s}$, so

$$
\bar{\tau}_{S}=\frac{\sum_{s \in S} N_{s} \tau_{s}}{\sum_{s \in S} N_{s}} .
$$
}


Given these two assumptions, we can simplify the expression in (E.3):

$$
\begin{aligned}
\varepsilon & =\frac{\mathrm{d} C G}{\mathrm{~d}\left(1-\tau_{F}-\bar{\tau}_{S}\right)} \cdot \frac{\left(1-\tau_{F}-\bar{\tau}_{S}\right)}{C G} \\
& =\left[\sum_{s \in S} N_{s} \frac{\mathrm{d} R_{s}}{\mathrm{~d}\left(1-\tau_{F}-\tau_{s}\right)}\right] \cdot \frac{\left(1-\tau_{F}-\bar{\tau}_{S}\right)}{\sum_{s \in S} N_{s} R_{s}} \\
& =\left[\sum_{s \in S} N_{s} \varepsilon^{R} \cdot \frac{R_{s}}{\left(1-\tau_{F}-\tau_{s}\right)}\right] \cdot \frac{\left(1-\tau_{F}-\bar{\tau}_{S}\right)}{\sum_{s \in S} N_{s} R_{s}} \\
& =\varepsilon^{R}\left[\sum_{s \in S} N_{s} \frac{R_{s}}{\left(1-\tau_{F}-\tau_{s}\right)}\right] \cdot \frac{\left(1-\tau_{F}-\bar{\tau}_{S}\right)}{\sum_{s \in S} N_{s} R_{s}} \\
& =\varepsilon^{R}\left[\sum_{s \in S} n_{s} \frac{R_{s}}{\left(1-\tau_{F}-\tau_{s}\right)}\right] \cdot \frac{\left[\sum_{s \in S} n_{s} \cdot\left(1-\tau_{F}-\tau_{s}\right)\right]}{\left[\sum_{s \in S} n_{s} R_{s}\right]}
\end{aligned}
$$

where $n_{s}$ is the population of the state expressed as a share of the national population. ${ }^{34}$ This expression now gives us the policy-relevant national elasticity as a function of the local realizations elasticity, $\varepsilon^{R}$, times an adjustment term which is somewhat difficult to interpret but deals with weighting among states. Essentially, it corrects for the fact that an elasticity measured at the aggregate level is not necessarily exactly equal to the mean of elasticities measured at a more granular level. Note that in our empirical setting, in every single year for which we have data, the adjustment factor is very close to 1 - its minimum value across all years is 0.993 , and its maximum is 1.004 . For this reason, $\varepsilon$ and $\varepsilon^{R}$ are in practice almost identical, which is why we present equation (6) for the revenue-maximzing tax rate in the main text with an $\varepsilon^{R}$, although it should be an $\varepsilon$ to be completely precise, as in equation (E.2). We use the 2016 value, which is 1.0025 , to adjust our empirical estimates when estimating $\varepsilon^{R}$ and the revenue-maximizing tax rates in section 4.3.

Equations (E.2) and (E.4) together tell us directly how to get an estimate of the revenue-maximizing tax rate from local elasticities. Since our empirically estimated elasticities at the state level give us $\varepsilon^{C G}=\varepsilon^{N}+\varepsilon^{S}$, we need an estimate of $\varepsilon^{N}$ to get the realizations elasticity. We do this in section 4 . of the paper by running a version of our direct projections with the outcome variable being a weighted combination of the log number of state residents that belong to the top $10 \%$ and the top $1 \%$ of the national wealth distribution, respectively. This can be thought of as applying our outlined model only to the top of the wealth distribution. Capital gains tax reforms are likely to have a limited impact on migration of individuals outside the top $10 \%$, and even if there is a migration effect for these individuals, it will not substantially affect overall capital gains realizations in the state, since individuals outside the top $10 \%$ only account for a very small share of capital gains realizations.

\section{Two-region example}

To make the above derivations a little more concrete, we present the following simple numerical example. Suppose the country consists of two regions: California $(c)$ and everywhere else $(e)$. Assume the following

\footnotetext{
${ }^{34}$ Formally, this is defined as
}

$$
n_{s}=\frac{N_{s}}{\sum_{q \in S} N_{q}}
$$


values: ${ }^{35}$

$$
\begin{aligned}
N_{c} & =20 \\
N_{e} & =80 \\
\kappa_{c} & =25 \\
\kappa_{e} & =22 \\
\tau_{c} & =0.14 \\
\tau_{e} & =0.05 \\
\tau_{F} & =0.25
\end{aligned}
$$

Suppose we estimate a total elasticity of capital gains $\hat{\varepsilon}^{C G}=3$ and a migration elasticity $\hat{\varepsilon}^{N}=1.5 .^{36}$ This implies a realization elasticity of $\hat{\varepsilon}^{R}=1.5$.

The average population-weighted state tax rate is $\bar{\tau}=0.2 \cdot 0.14+0.8 \cdot 0.05=0.068$. Using equation (E.4) above, we thus find the policy-relevant elasticity $\varepsilon$ above to be

$$
\begin{aligned}
\varepsilon & =\varepsilon^{\kappa}\left[\sum_{s \in S} n_{s} \frac{R_{s}}{\left(1-\tau_{F}-\tau_{s}\right)}\right] \cdot \frac{\left[\sum_{s \in S} n_{s}\left(1-\tau_{F}-\tau_{s}\right)\right]}{\left[\sum_{s \in S} n_{s} R_{s}\right]} \\
& =1.5 \cdot\left[\frac{0.2 \cdot 25}{0.61}+\frac{0.8 \cdot 22}{0.7}\right] \cdot \frac{0.2 \cdot 0.61+0.8 \cdot 0.7}{0.2 \cdot 25+0.8 \cdot 22} \\
& =1.5 \cdot 1.006 \\
& =1.509 .
\end{aligned}
$$

The revenue-maximizing national capital gains tax rate implied by this elasticity is thus

$$
\tau_{F}^{*}=\frac{1-\bar{\tau}_{S}}{1+\varepsilon}=\frac{1-0.068}{1+1.509}=0.371 .
$$

\footnotetext{
${ }^{35}$ These values are roughly consistent with actual numbers for people in the top $10 \%$ of the wealth distribution in the US in 2016, with the population rebased to 100 individuals and the realized capital gains per capita given in thousands of dollars.

${ }^{36}$ These values are close to what we find in our specification using big tax changes only.
} 